\title{
Optimization of Fins Arrangements for the Square Light Edding Diode (LED) Cooling through Nanofluid-Filled Microchannel
}

Mohamed Bechir Ben Hamida

Ha'il University

Mohammad Hatami ( $\nabla$ m.hatami@xjtu.edu.cn )

Ferdowsi University of Mashhad

\section{Research Article}

Keywords: LED cooling, Al203-water nanofluid, Optimization, Finned Micro-channel, Response Surface Method

Posted Date: April 13th, 2021

DOI: https://doi.org/10.21203/rs.3.rs-411757/v1

License: (c) (i) This work is licensed under a Creative Commons Attribution 4.0 International License. Read Full License 


\title{
Optimization of Fins Arrangements for the Square Light Edding Diode (LED) Cooling through Nanofluid-Filled Microchannel
}

\author{
Mohamed Bechir Ben Hamida ${ }^{a, b}$, Mohammad Hatami ${ }^{c, 1}$ \\ ${ }^{a}$ Chemical Engineering Department, College of Engineering, Ha'il University, Ha'il City, Saudi Arabia \\ ${ }^{\mathrm{b}}$ Research Unit of Ionized Backgrounds and Reagents Studies (UEMIR), Preparatory Institute for \\ Engineering Studies of Monastir (IPEIM),5019 Kairouan street, University of Monastir, Tunisia. \\ ${ }^{\mathrm{c}}$ Mechanical Engineering Department, Ferdowsi University of Mashhad, Mashhad, Iran
}

\section{Abstract}

In current paper, a finned micro-channel is designed for the cooling application in Light Edding Diode (LED), numerically. Selected materials for LED-chip is GaN, Die from $\mathrm{Si}$, Die-attach is made by Au-20Sn, substrate is copper and heat sink material is considered to be $\mathrm{Al}$. To make a convection heat transfer for cooling process, $\mathrm{Al}_{2} \mathrm{O}_{3}$-water nanofluid is used as the cooling fluid flow through the micro-channel and tried to maximize the heat transfer efficiency by optimized geometry. For this aim, there geometry variables from the microchannel were selected and minimum possible geometry cases (11cases) were proposed by Central composite design (CCD) and variables were optimized by the Response Surface Method (RSM). As a main result, parameter B, i.e. fin length had the most effect on the Nusselt number and $\mathrm{Al}_{2} \mathrm{O}_{3}$ nanoparticles with $\varphi=0.01$ stated greatest heat transfer value.

Keywords: LED cooling; $\mathrm{Al}_{2} \mathrm{O}_{3}$-water nanofluid; Optimization; Finned Microchannel; Response Surface Method.

\section{Introduction}

Light Edding Diode or LED lamps have taken the place of discharge lamps such as mercury discharge lamps $[1,2]$ and metal halide lamp[3,4] due to better energy efficiency,

\footnotetext{
${ }^{1}$ Corresponding authors, E-mails: m.hatami@xjtu.edu.cn (M. Hatami), Tel/Fax:+98-935-860-2679
} 
small size, environmental friendliness, low UV radiation, easy control and low maintenance. So, due to this advantages of LED lamps, many researchers focused on its improvements and optimizations. For instance, Ben Salah and Ben Hamida [5, 6] investigated the heat transfer in LED geometries using air and PCM as alternative cooling materials. They also compared the results based on Ha and Graham [7] study for a chipon-board packing of LED arrays with high power. So, Ben Hamida et al. [8] optimized some parameters such as: thickness, material and size of all subcomponents for single-chip LED to reduce the junction temperature and increase light output as well as device reliability. They considered six parts for the case modeling named die, die-attach, metallization, thermal interface material, substrate and heat sink to find the best material and concluded that $\mathrm{GaN}$ as LED-Chip material, $\mathrm{SiC}$ for Die material, $\mathrm{Au}$ as material metallization, 100In for Die-attach material, AIN DBC was the greatest substrate package, Copper for heat sink was the most suitable material and 100In solder as thermal Interface Material for designated parts. Also, other suitable materials are proposed by researchers such as $\mathrm{CsPbBr} 3$ as the perovskite light emitting diodes proposed by Jia et al. [9]. Yu et al. [10] investigated the LED performance covered by cesium lead halide perovskite $\mathrm{CsPbBr} 3$ through a small organic molecule material named 1, 3, 5-tri (m-pyrid-3-yl-phenyl) benzene (TmPyPB) as a chemical stabilizer. In an experimental study about the LED cooling, Pan et al. [11] used the cutting copper fiber oriented sintered heat sinks (CCFOSHS) and found that by decreasing the porosity, heat transfer efficiency of CCFOSHS was improved slightly, but pressure drops were increased, noticeably. Lin et al. [12] used the nanofluidcooled microchannel heat sink for the light-emitting diodes (LEDs) and concluded that nanofluids reduced the thermal resistance more than $42.4 \%$ where $0.5 \% \mathrm{TiO}_{2}$ nanofluid 
improved the heat transfer efficiency up to $38.6 \%$ compared to pure water. Another study on LED cooling improvements is performed by Lin et al. [13] using Taguchi parametric study for the micro-channel. Also, Huang and Wang [14] found the optimal fins geometry for the circular micro-channel of LED lighting heat sinks, numerically. They found that thermal resistance of systems for the optimum design were decreased by $16.8 \%$ and $11.0 \%$ than the "initial" and "Type 2" design heat sinks, respectively.

There are also some researchers focused on the novel designs for LED heat sink applications to improve the thermal managements. Wang et al. [15] designed novel tubular oscillating heat pipe with sintered copper particles for this application and reported that the temperature of LED array was inversely related to the illumination intensity. Tang et al. [16] developed an integrated heat sink with vapor chamber for LED thermal managements and showed that the high-power LED yields a favorable performance using proposed unit. Kim et al. [17] proposed the using cupper-oxide $(\mathrm{CuO})$ composite coating on aluminumalloy heat sink to enhance the heat dissipation of LED module and observed good results due to the improved thermal radiation property. In a different study, Park et al. [18, 19] designed a chimney over a circular heat sink in a downlight LED and reported that installing chimney can increase the cooling efficiency of heat sink up to $20 \%$. Microchannels not only is applicable for LED cooling, but also they are very useful instruments for thermoelectric generators [20], natural circulation loops [21] and etc. which different base fluids such as PCM [22] and nanofluids [23] are widely used to improve their performance.

Nanofluids due to improvements thermal properties have wide applications and motivated researchers to use them in various aspects. Ben Hamida et al. [24] used Ethylene 
Glycol-Copper Nanofluid under magnetic fields in an enclosure. Ben Jaballah et al. [25] applied the hybrid nanofluid for the performance enhancement of bubble absorber for cooling applications. Hatami and Ganji [26], Hatami et al. [27] and Tang et al. [28] used the nanofluid in porous media between two coaxial cylinders, wavy microchannel and wavy cavity, respectively. Also, Hatami et al. [29-32] used the optimization techniques such as Response Surface Methodology (RSM) to find the optimize geometries including nanofluids in heat transfer applications. Massoudi et al. [33, 34] also investigated the nanofluids application in free convection under the influence of magnetic field.

Based on discussed short literature review, here it is tried to enhance the cooling efficiency of a LED by using the $\mathrm{Al}_{2} \mathrm{O}_{3}$-water nanofluid and finned arrangements in a microchannel, simultaneously. Also, RSM is used to find the optimized dimensions for the fin numbers, lengths and thicknesses, numerically.

\section{Problem Description}

A 3D microchannel filled by $\mathrm{Al}_{2} \mathrm{O}_{3}$-water nanofluid is considered as shown in Fig. 1 for LED cooling by fin arrangements. Microchannel dimensions are: Height $=100 \mathrm{~mm}$; Width $=80 \mathrm{~mm}$ and Depth $=50 \mathrm{~mm}$ and the Power of $\mathrm{LED}=1,2$ and $3 \mathrm{~W}$ as shown in Table 1 in details. The velocity of inlet of nanofluid was considered as $0.001 \mathrm{~m} / \mathrm{s}$ where the temperature of inlet of nanofluid considered to be $25^{\circ} \mathrm{C}$. The micro-channel is equipped with fin arrangements for better cooling performance. The main objective of current research is finding the optimum values for fin numbers, lengths and thicknesses, respectively as shown in Fig. 1 for the micro-channel geometry. For modeling the problem, a transient flow, incompressible three-dimensional flow from the laws of conservation of 
mass, momentum, and energy is considered. The governing equations represent the transient flows are [8]:

\section{Mass conservation equation:}

$$
\frac{\partial \rho}{\partial t}+\frac{\partial(\rho u)}{\partial x}+\frac{\partial(\rho v)}{\partial y}+\frac{\partial(\rho w)}{\partial z}=0
$$

Where $\rho$ refers to the mass density and $\mathrm{u}, \mathrm{v}$, and $\mathrm{w}$ represent the velocities according to $\mathrm{x}, \mathrm{y}$, and $\mathrm{z}$, respectively.

Momentum conservation equation according to $\mathrm{x}$ :

$$
\frac{\partial(\rho u)}{\partial t}+\frac{\partial(\rho u u)}{\partial x}+\frac{\partial(\rho u v)}{\partial y}+\frac{\partial(\rho u w)}{\partial z}=-\frac{\partial p}{\partial x}+\left[\frac{\partial}{\partial x}\left(\eta \frac{\partial u}{\partial x}\right)+\frac{\partial}{\partial y}\left(\eta \frac{\partial u}{\partial y}\right)+\frac{\partial}{\partial z}\left(\eta \frac{\partial u}{\partial z}\right)\right]
$$

Momentum conservation equation according to $y$ :

$$
\frac{\partial(\rho v)}{\partial t}+\frac{\partial(\rho u v)}{\partial x}+\frac{\partial(\rho v v)}{\partial y}+\frac{\partial(\rho v w)}{\partial z}=-\frac{\partial p}{\partial y}+\left[\frac{\partial}{\partial x}\left(\eta \frac{\partial v}{\partial x}\right)+\frac{\partial}{\partial y}\left(\eta \frac{\partial v}{\partial y}\right)+\frac{\partial}{\partial z}\left(\eta \frac{\partial v}{\partial z}\right)\right]+\rho g
$$

\section{Momentum conservation equation according to z:}

$$
\frac{\partial(\rho w)}{\partial t}+\frac{\partial(\rho u w)}{\partial x}+\frac{\partial(\rho v w)}{\partial y}+\frac{\partial(\rho w w)}{\partial z}=-\frac{\partial p}{\partial z}+\left[\frac{\partial}{\partial x}\left(\eta \frac{\partial w}{\partial x}\right)+\frac{\partial}{\partial y}\left(\eta \frac{\partial w}{\partial y}\right)+\frac{\partial}{\partial z}\left(\eta \frac{\partial w}{\partial z}\right)\right]
$$

In above equations, $\mathrm{p}$ denotes the pressure, $\mathrm{g}$ shows the gravity, and $\eta$ is related to the dynamic viscosity.

\section{Energy conservation equation:}

$$
\frac{\partial(\rho C T)}{\partial t}+\frac{\partial(\rho u C T)}{\partial x}+\frac{\partial(\rho v C T)}{\partial y}+\frac{\partial(\rho w C T)}{\partial z}=\left[\frac{\partial}{\partial x}\left(\lambda \frac{\partial T}{\partial x}\right)+\frac{\partial}{\partial y}\left(\lambda \frac{\partial T}{\partial y}\right)+\frac{\partial}{\partial z}\left(\lambda \frac{\partial T}{\partial z}\right)\right]
$$

Where, $\mathrm{T}$ and $\mathrm{C}$ are the temperature and the specific heat capacity, respectively and $\lambda$ is the thermal conductivity.

The practical boundary conditions are assumed as follows:

- There is a uniform heat flux on top of the die, and other surfaces are adiabatic. 
- The microchannel inlet boundary condition is considered to be the uniform temperature of $T_{\text {in }}$ with a uniform velocity of $U_{\text {in }}$.

- At microchannel outlet, Pressure outlet boundary condition with zero gradients is assumed.

- No slip condition is imposed on the surface of microchannel walls.

- All the microchannel outer walls are insulated.

In this study, the thermal conductivity of the materials used in the LED package as well as the water properties are considered dependent on temperature [8]. For water temperature-dependent properties:

\section{a) Dynamic viscosity:}

$273.15 \mathrm{~K}<\mathrm{T}<473.15 \mathrm{~K}:$

$\eta=1.3799566804-0.021224019151 * \mathrm{~T}+1.3604562827 * 10^{-4} * \mathrm{~T}^{2}-4.6454090319 * 10^{-7} * \mathrm{~T}^{3}+$

$8.9042735735 * 10^{-10^{*}} \mathrm{~T}^{4}-9.0790692686 * 10^{-13} * \mathrm{~T}^{5}+3.8457331488 * 10^{-16} * \mathrm{~T}^{6}$

$473.15<\mathrm{T}<553.15 \mathrm{~K}:$

$\eta=0.00401235783-2.10746715^{*} 10^{-5 *} \mathrm{~T}+3.85772275^{*} 10^{-8 *} \mathrm{~T}^{2}-2.39730284 * 10^{-11 *} \mathrm{~T}^{3}$

$\mathrm{T}$ in $\mathrm{K}$ and dynamic viscosity in Pa.s

\section{B) Thermal Capacity:}

$$
273.15<\mathrm{T}<553.15 \mathrm{~K}
$$

$\mathrm{C}=12010.1471-80.4072879 * \mathrm{~T}+0.309866854 * \mathrm{~T}^{2}-5.38186884 * 10^{-4 *} \mathrm{~T}^{3}+3.62536437 * 10^{-7} * \mathrm{~T}^{4}$

$\mathrm{T}$ in $\mathrm{K}$ and Thermal Capacity in $\mathrm{J} /(\mathrm{kg} * \mathrm{~K})$

\section{D) Mass density}

$$
\begin{aligned}
& 273.15<\mathrm{T}<293.15 \mathrm{~K} \\
& \quad=\quad 0.000063092789034 * \mathrm{~T}^{3}-0.060367639882855 * \mathrm{~T}^{2}+18.9229382407066 * \mathrm{~T} \\
& 950.704055329848
\end{aligned}
$$

$293.15<\mathrm{T}<373.15 \mathrm{~K}$ 
$\mathrm{T}$ in $\mathrm{K}$ and mass density in $\mathrm{kg} / \mathrm{m}^{3}$

\section{E) Thermal conductivity}

$273.15<\mathrm{T}<1000 \mathrm{~K}$

$\lambda=-0.869083936+0.00894880345 * \mathrm{~T}-1.58366345 * 10^{-5} * \mathrm{~T}^{2}+7.97543259 * 10^{-9} * \mathrm{~T}^{3}$

$\mathrm{T}$ in $\mathrm{K}$ and Thermal conductivity in $\mathrm{W} /\left(\mathrm{m}^{*} \mathrm{~K}\right)$. For the nanofluid properties, following equations are applied [35]:

$$
\begin{aligned}
& \rho_{n f}=(1-\phi) \rho_{b f}+\varphi \rho_{p} \\
& C_{p_{n f}}=\frac{(1-\varphi)\left(\rho C_{p}\right)_{b f}+\varphi\left(\rho C_{p}\right)_{p}}{\rho_{n f}} \\
& \frac{k_{n f}}{k_{b f}}=0.991+0.276 T \varphi+77.6 \varphi^{2}+3641.231 T \varphi^{2}+ \\
& \frac{0.00217}{\sin (T-\varphi)}-6.01 \times 10^{-6} T^{2}-3647.099 T \varphi \sin (\varphi) \\
& \mu_{n f}=\mu_{\text {static }}+\mu_{\text {Brownian }} \\
& \mu_{n f}=\frac{\mu_{f}}{(1-\varphi)^{2.5}}+5 \times 10^{4} \beta \varphi \rho_{f}\left(C_{p}\right)_{f} \frac{\mu_{f}}{k_{f} \operatorname{Pr}} \sqrt{\frac{k_{b} T}{\rho_{p} d_{s}}} f(T, \varphi)
\end{aligned}
$$

where

$$
\begin{aligned}
& f(T, \varphi)=\left(2.8217 \times 10^{-2} \varphi+3.917 \times 10^{-3}\right)\left(\frac{T}{T_{0}}\right)+\left(-3.0669 \times 10^{-2} \varphi-3.91123 \times 10^{-3}\right) \\
& \beta=8.4407(100 \varphi)^{-1.07304}
\end{aligned}
$$

\section{Methodology of Solution}

In this study, COMSOL-Multiphysics 5.4 commercial finite element method (FEM software is applied for the modeling of problem. FEM is a numerical method to discretize and solve the coupled partial differential equations governed on any physical phenomenon. FEM by COMSOL not only is accurate and adaptable, but also it is simple in modeling the 
complicated physics as well as the time-dependent simulation of physical problems in environment, chemical, energy, electrical, heat transfer and other multi-physic problems. Actually, FEM with COMSOL can help the user to solve the problems with multi-physic such as electrical-mechanical systems easily, while the solution of these problems by other commercial software (such as FVM based ANSYS-FULENT) or by hand is not possible [8]. During the modeling process, user must define the boundary conditions after the geometry modeling to show the conditions which must be responded during the solution. Boundary conditions can be defined as the distributed forces, point forces, positional constraints and thermal effects such as temperature changes or applied heat energy. Additionally, the FEM user can certainly spot any vulnerability in design with the complete visualizations FEM produces and then use the novel data to have a new design [8].

Central Composite Design or CCD is a technique of Design of Experiment (DoE) to achieve the suitable points of each independent variable based on their possible values (level). CCD contains an imbedded factorial or fractional factorial design with center points which is improved by a "star points" group and let's estimate of curvature. After introducing the minimum number of cases with CCD, RSM must be applied to find the optimum values for the fin numbers, lengths and thicknesses. Actually, RSM find a first or second-order polynomial relation between the response (here temperature) and independent variables (fin numbers, lengths and thicknesses). This polynomial equation consider the interaction between the and surface curvatures and fitted in the shape of [ 31 , 32] 


$$
y=A_{0}+\sum_{i=1}^{n} A_{i} x_{i}+\sum_{i=1}^{n} A_{i i} x_{i}^{2}+\left.\sum_{i=1}^{n} \sum_{j=1}^{n} A_{i j} x_{i} x_{j}\right|_{i<j}
$$

where $x_{i}$ and $x_{j}$ indicate the geometry independent variables (fin numbers, lengths and thicknesses) and $A$ is the coefficient of polynomial equation. The essential parameter for RSM optimization is "Desirability" which returns the desirable ranges of responses $\left(\mathrm{d}_{\mathrm{i}}\right)$. Actually, objective function can be altered from zero outside of the limits to unity at the aim and the point with the maximum desirability function by following equation is the optimized case obtained by numerical solutions:

$$
D=\left(d_{1} \times d_{2} \times \ldots \times d_{n}\right)^{\frac{1}{n}}=\left(\prod_{i=1}^{n} d_{i}\right)^{\frac{1}{n}}
$$

where $n$ indicates the number of responses. If each of responses or factors drops outside their desirability range, the overall function will be zero. More details about this optimization method can be found in $[31,32]$.

\section{Results and Discussions}

As described in above sections, it is tried to obtain an optimized geometry for the nanofluid microchannel for LED cooling. Dimensions of LED package as well as the materials are presented in Table 1. Based on previous study in [8], the best materials for LED-chip is GaN, Die from Si, Die-attach is made by Au-20Sn, substrate is copper and heat sink material is considered to be Al. LED had 1,2 and $3 \mathrm{~W}$ power and the microchannel dimensions was Height $=100 \mathrm{~mm}$; Width $=80 \mathrm{~mm}$ and Depth $=50 \mathrm{~mm}$. In order to find a suitable mesh grid, numerous mesh numbers (from extremely coarse to finer mesh) were used for this 3D model as demonstrated in Table 2. This values confirm that fine mesh is a suitable grid type for this study due to its accuracy and acceptable time of 
calculations. Here, CCD is applied to have the proposed geometries for the considered parameters as shown in Table 3. Fin number, fin diameter and fin thicknesses are three main parameters under the study which their levels are presented in Table 3. CCD proposed 11 cases as shown in Table 4 in details.

To validate our generated 3D model with the previous model of Ha and Graham [7], the temperature distribution of the LED package is simulated with the equivalent settings modeled by $\mathrm{Ha}$ and Graham [7] as presented in Fig. 1 and generated mesh is depicted in Fig. 2. Fig. 3 shows the 3D model simulated by Ha and Graham [7] using the commercial ANSYS-FLUENT software where Power of LED lamp was 1W, heat transfer coefficient was $10 \mathrm{~W} / \mathrm{m}^{2} / \mathrm{K}$ and the temperature of ambient was $25^{\circ} \mathrm{C}$. From the Fig. 3 (a,b) it can be observed that current code has similar results where the minimum and maximum temperatures are around $53.22^{\circ} \mathrm{C}$ and $60.37^{\circ} \mathrm{C}$, respectively for both methods. Actually a minor temperature difference between the two models is existed which does not exceed than $0.001 \%$. Also, the vertical temperature profile along the LED package centerline is plotted in Fig. 3 (c), which a good agreement between current 3D COMSOL-Multiphysics model and 3D ANSYS-FLUENT model of Ha and Graham [7] was evident.

Figs. 4, 5 and 6 show the temperatures, velocities and streamlines of nanofluid in both LED and microchannel domains and the results of junction temperature for three LED powers $(1,2$ and $3 \mathrm{~W})$ of all 11 designed cases are shown in Table 5 at final time, $t=620 \mathrm{~s}$. Fig. 7 and Fig. 8 shows the 2D contours of velocity and streamlines of 11 cases, respectively. It can be observed that cases 6,8 and 9 due to greater fin numbers ( 8 fins) has more compact microchannel and the velocity between the fins is smaller. But for the cases 2, 3 and 5 nanofluids easily flow between the fins due to more free spaces. So, this 
parameter has an important role in heat transfer. Also, the cases which have lengthy fins (Cases 1, 5 and 9) have smaller region of maximum velocity in micro-channel (red area) due to making obstacles against the flow. Because these three parameters has influence on each other, a parametric study is required to find the most important parameter among them. Fig. 9 shows the average temperatures during the time for $\mathrm{P}=3 \mathrm{~W}$. Cases 3,10 and 6 have maximum temperatures (worst cooling performance) and cases 9, 1 and 5 have the minimum temperatures or best cooling performances. From Table 4 it can be seen that Cases 3, 10 and 6 are in lowest level of fin length, while cases 9, 1 and 5 are in upper level of fins length. Fig. 10 and Fig. 11 also present the temperatures during the time when LED power is $2 \mathrm{~W}$ and $1 \mathrm{~W}$, respectively which confirm the same results. Also, it can be found that number of fins is the next important parameter while the fins thickness is the last parameter due to its small effect of the cooling performance. Fig. 12 shows these descriptions in $2 \mathrm{D}$ and $3 \mathrm{D}$ contours to find the effect of each parameter on the results. As seen, slope of curves and surfaces for the parameter $B$ is greater than parameter $A$ and greater than parameter $C$. Also the minimum temperatures (best cooling) is occurred when all the parameters are in upper levels, so desirability function of optimized case in Fig. 13 is depicted which illustrate that better case (desirability=1) occurs when $B=20$ and $A=8$. Based on these results, RSM proposed the best cases which is presented in Table 6 as optimized geometries. Fig. 14 compares the Nusselt number and pressure drops of all cases. Since the pressure drops are very small, so they can be negligible in optimization and single objective is performed for this case of study. The results of optimized case is depicted in Fig. 15, while the effect of different nanoparticles volume fraction is presented in Fig. 16 
which says that smaller nanoparticles volume fraction has greater Nusselt number due to temperature dependent properties of base water.

\section{Conclusion}

In this study, the geometry of a finned microchannel is optimized for application in LED cooling by nanofluids, numerically. COMSOL-Multiphysic commercial code was used and $\mathrm{Al}_{2} \mathrm{O}_{3}$-water as the cooling nanofluid flow was selected as the working fluid. Three powers (1, 2 and $3 \mathrm{~W})$ are used for the LED power output and to find the optimized arrangement of fins for reaching the minimum temperature (as cooling efficiency), Central composite design (CCD) was applied to propose minimum possible geometries (11 Cases). Finally, FEM results of modeling were optimized by the Response Surface Method (RSM) which confirmed that the optimized case include parameters as Fin numbers $=8$, Fin length $=20$ and Fin thickness $=4$ where nanoparticles with $\varphi=0.01$ caused maximum cooling efficiency for this case.

\section{References}

[1] Ben Hamida M. B, Charrada K. Application of a three-dimensional model for a study of the energy transfer of a high-pressure mercury horizontal lamp. Physics of Plasmas. 2012; 19(6), 063504.

[2] Ben Hamida M.B, Helali H, Araoud Z, Charrada K. Contrast between the vertical and horizontal mercury discharge lamps, Physics of Plasmas. 2011, 18(6), 063506.

[3] Ben Hamida M. B, Charrada K. A three-dimensional thermal study of a mercury discharge lamp with double envelope for different orientations, Journal of physics plasmas. 2014; 81(2), 905810202.

[4] Ferjani B, Ben Hamida M.B. Thermal study of the atomic ratio effect on a cylindrical and an ellipsoidal shaped HgTII discharge lamps. The European Physical Journal D. 2019; 73(9), 208. 
[5] Ben salah S, Ben Hamida M.B. Heat transfer enhancement of circular and square LED geometry. International journal of numerical methods for heat and fluid flow.2019; 29(5), 1877-1898.

[6] Ben Salah S, Ben Hamida M.B. Alternate PCM with air cavities in LED heat sink for transient thermal management. International Journal of Numerical Methods for Heat \& Fluid Flow. 2019; https://doi.org/10.1108/HFF-02-2019-0099.

[7] Ha M., Graham S. Development of a thermal resistance model for chip-on-board packaging of high power LED arrays. Microelectronics Reliability. 2012; 52(5), 836-844.

[8] Mohamed Bechir Ben Hamida, Kamel Charrada, Mohammed A. Almeshaal, Ali Chamkha, A three-dimensional thermal analysis and optimization of square light edding diode subcomponents, International Communications in Heat and Mass Transfer xxx (xxxx) $\mathrm{xxx}$

[9] Ya-Lan Jia, Run Wang, Yue Zhang, Xing-Juan Ma, Fu-Xing Yu, Zi-Yang Xiong, Dong-Ye Zhou, Zu-Hong Xiong, Chun-Hong Gao, Large current efficiency enhancement in the $\mathrm{CsPbBr} 3$ perovskite light-emitting diodes assisted by an ultrathin buffer layer, Journal of Luminescence 209 (2019) 251-257.

[10] Fu-Xing Yu, Yue Zhang, Zi-Yang Xiong, Xing-Juan Ma, Ping Chen, Zu-Hong Xiong, Chun-Hong Gao, Full coverage all-inorganic cesium lead halide perovskite film for highefficiency light-emitting diodes assisted by 1,3,5-tri(m-pyrid-3-yl-phenyl)benzene, Organic Electronics 50 (2017) 480e484.

[11] Minqiang Pan, Haozhong $\mathrm{Hu}$, Guanping Dong, Experimental study of the performance of cutting copper fiber oriented sintered heat sinks for the water cooling of LEDs, Applied Thermal Engineering 179 (2020) 115738.

[12] Xiaohui Lin, Songping Mo, Bingzhong Mo, Lisi Jia, Ying Chen, Zhengdong Cheng, Thermal management of high-power LED based on thermoelectric cooler and nanofluidcooled microchannel heat sink, Applied Thermal Engineering 172 (2020) 115165.

[13] Xiaohui Lin, Songping Mo, Lisi Jia, Zhi Yang, Ying Chen, Zhengdong Cheng, Experimental study and Taguchi analysis on LED cooling by thermoelectric cooler integrated with microchannel heat sink, Applied Energy 242 (2019) 232-238. 
[14] Cheng-Hung Huang, Guan-Jie Wang, A design problem to estimate the optimal fin shape of LED lighting heat sinks, International Journal of Heat and Mass Transfer 106 (2017) 1205-1217

[15] Hai Wang, Jian Qu, Youquan Peng, Qin Sun, Heat transfer performance of a novel tubular oscillating heat pipe with sintered copper particles inside flat-plate evaporator and high-power LED heat sink application, Energy Conversion and Management 189 (2019) 215-222

[16] Yong Tang, Lang Lin, Shiwei Zhang, Jian Zeng, Kairui Tang, Gong Chen, Wei Yuan, Thermal management of high-power LEDs based on integrated heat sink with vapor chamber, Energy Conversion and Management 151 (2017) 1-10.

[17] Donghyun Kim, Junghoon Lee, Junho Kim, Chang-Hwan Choi, Wonsub Chung, Enhancement of heat dissipation of LED module with cupric-oxide composite coating on aluminum-alloy heat sink, Energy Conversion and Management 106 (2015) 958-963.

[18] Seung-Jae Park, Daeseok Jang, Se-Jin Yook, Kwan-Soo Lee, Optimization of a chimney design for cooling efficiency of a radial heat sink in a LED downlight, Energy Conversion and Management 114 (2016) 180-187.

[19] Seung-Jae Park, Daeseok Jang, Kwan-Soo Lee, Thermal performance improvement of a radial heat sink with a hollow cylinder for LED downlight applications, International Journal of Heat and Mass Transfer 89 (2015) 1184-1189.

[20] Junwei Liu, Ying Zhang, Debao Zhang, Shifei Jiao, Zhuofen Zhang, Zhihua Zhou, Model development and performance evaluation of thermoelectric generator with radiative cooling heat sink, Energy Conversion and Management 216 (2020) 112923

[21] C.J. Ho, Y.N. Chung, Chi-Ming Lai, Thermal performance of Al2O3/water nanofluid in a natural circulation loop with a mini-channel heat sink and heat source, Energy Conversion and Management 87 (2014) 848-858

[22] Cyril Reuben Raj, S. Suresh, Sudharshan Vasudevan, M. Chandrasekar, Vivek Kumar Singh, R.R. Bhavsar, Thermal performance of nano-enriched form-stable PCM implanted in a pin finned wall-less heat sink for thermal management application, Energy Conversion and Management 226 (2020) 113466 
[23] Hatami, M., and D. D. Ganji. "Thermal and flow analysis of microchannel heat sink (MCHS) cooled by $\mathrm{Cu}$-water nanofluid using porous media approach and least square method." Energy Conversion and management 78 (2014): 347-358.

[24] Ben Hamida M.B, Charrada K. Natural Convection Heat Transfer in an Enclosure Filled with an Ethylene Glycol-Copper Nanofluid under Magnetic Fields. Numerical Heat Transf, Part A: Applications: An International Journal of Computation and Methodology. 2015; 67(8), 902-92.

[25] Ben Jaballah R, Ben Hamida M.B, Saleh J, Almeshaal M.A. Enhancement of the performance of bubble absorber using hybrid nanofluid as a cooled absorption system. International journal of numerical methods for heat and fluid flow. 2019; 29(10), 385738719.

[26] Hatami M., Ganji, D. D. Heat transfer and flow analysis for $\mathrm{SA}^{-\mathrm{TiO}_{2}}$ non-Newtonian nanofluid passing through the porous media between two coaxial cylinders. Journal of Molecular Liquids. 2013; 188, 155-161. doi:10.1016/j.molliq.2013.10.009

[27] Zhou, Jiandong, M. Hatami, Dongxing Song, and Dengwei Jing. "Design of microchannel heat sink with wavy channel and its time-efficient optimization with combined RSM and FVM methods." International Journal of Heat and Mass Transfer 103 (2016): 715-724.

[28] Tang, Wenhui, M. Hatami, Jiandong Zhou, and Dengwei Jing. "Natural convection heat transfer in a nanofluid-filled cavity with double sinusoidal wavy walls of various phase deviations." International Journal of Heat and Mass Transfer 115 (2017): 430-440.

[29] Hatami, M., D. Song, and D. Jing. "Optimization of a circular-wavy cavity filled by nanofluid under the natural convection heat transfer condition." International Journal of Heat and Mass Transfer 98 (2016): 758-767.

[30] Hatami, M. "Nanoparticles migration around the heated cylinder during the RSM optimization of a wavy-wall enclosure." Advanced Powder Technology28, no. 3 (2017): 890-899.

[31] Hatami, M., and D. Jing. "Optimization of wavy direct absorber solar collector (WDASC) using Al 2 O 3-water nanofluid and RSM analysis." Applied Thermal Engineering 121 (2017): 1040-1050. 
[32] Hatami, M., J. Zhou, J. Geng, D. Song, and D. Jing. "Optimization of a lid-driven Tshaped porous cavity to improve the nanofluids mixed convection heat transfer." Journal of Molecular Liquids 231 (2017): 620-631.

[33] Massoudi M.D., Ben Hamida M.B., Almeshaal M.A., Free convection and thermal radiation of nanofluid inside nonagon inclined cavity containing a porous medium influenced by magnetic field with variable direction in the presence of uniform heat generation/absorption, International Journal of Numerical Methods For Heat and Fluid Flow, 2020, doi.org/10.1108/HFF-04-2020-0223.

[34] Massoudi M.D., Ben Hamida M.B., MHD natural convection and thermal radiation of diamond-water nanofluid around rotating elliptical baffle inside inclined trapezoidal cavity, The European Physical Journal Plus, 2020, 135: 1-24.

[35] Jalal Alsarraf, Amin Shahsavar, Mahsa Khaki, Ramin Ranjbarzadeh, Arash Karimipour, Masoud Afrand, Numerical investigation on the effect of four constant temperature pipes on natural cooling of electronic heat sink by nanofluids: A multifunctional optimization, Advanced Powder Technology xxx (xxxx) xxx. 
Tables and Figures

Table 1. Properties of dimensions and materials of LED package

\begin{tabular}{cccc}
\hline & Thickness & Size & Materials \\
\hline LED-chip & $4 \mu \mathrm{m}$ & $1 \mathrm{~mm} \times 1 \mathrm{~mm}$ & GaN \\
Metallization: & $10 \mu \mathrm{m}$ & & Au-Si eutectic bonding \\
Bonding Layer & & & Si \\
Die & $375 \mu \mathrm{m}$ & & Au-20Sn \\
Die-attach & $50 \mu \mathrm{m}$ & & Copper \\
Substrate & $127 \mu \mathrm{m}$ & $1 \mathrm{~cm} \times 1 \mathrm{~cm}$ & AlN \\
& $381 \mu \mathrm{m}$ & & Thermal grease \\
TIM & $50 \mu \mathrm{m}$ & $1 \mathrm{~cm} \times 1 \mathrm{~cm}$ & Al \\
Heat sink & - & - & \\
\hline
\end{tabular}

Table 2. Mesh independency of the micro-channel

\begin{tabular}{cccc}
\hline $\begin{array}{c}\text { Predefined mesh } \\
\text { size }\end{array}$ & $\begin{array}{c}\text { Mesh } \\
\text { elements }\end{array}$ & $\begin{array}{c}\text { Junction Temperature } \\
\left({ }^{\circ} \mathbf{C}\right)\end{array}$ & $\begin{array}{c}\text { Temperature of } \\
\text { Heat sink }\left({ }^{\circ} \mathbf{C}\right)(\mathbf{m i n} . \\
\text { temperature) }\end{array}$ \\
\hline Extremely coarse & 3641 & 60.165 & 52.416 \\
Extra coarse & 6019 & 60.231 & 52.623 \\
Coarser & 10766 & 60.254 & 52.794 \\
Coarse & 17989 & 60.273 & 52.931 \\
Normal & 26436 & 60.289 & 53.087 \\
Fine & 45255 & 60.370 & 53.222 \\
Finer & 136857 & 60.968 & 53.568 \\
\hline
\end{tabular}

Table 3 Geometry parameters of fins arrangement for microchanel and defined levels

\begin{tabular}{ccccc}
\hline Parameter & Description & Level 1 & Level 2 & Level 3 \\
\hline A & Fin number & 4 & 6 & 8 \\
B & Fin Length & 10 & 15 & 20 \\
C & Fin thickness & 2 & 3 & 4 \\
\hline
\end{tabular}


Table 4 CCD proposed cases for finned geometry with Power of LED $=1,2$ and $3 \mathrm{~W}$ Microchannel dimensions: Height $=100 \mathrm{~mm}$; Width $=80 \mathrm{~mm}$ and Depth $=50 \mathrm{~mm}$

\begin{tabular}{cccc}
\hline Case Number & \multicolumn{3}{c}{ Level of parameters } \\
\cline { 2 - 4 } $\mathbf{1}$ & Parameter, A & Parameter, B & Parameter, C \\
$\mathbf{2}$ & 6 & 20 & 3 \\
$\mathbf{3}$ & 4 & 15 & 3 \\
$\mathbf{4}$ & 4 & 10 & 2 \\
$\mathbf{5}$ & 6 & 15 & 3 \\
$\mathbf{6}$ & 4 & 20 & 4 \\
$\mathbf{7}$ & 8 & 10 & 4 \\
$\mathbf{8}$ & 6 & 15 & 2 \\
$\mathbf{9}$ & 8 & 15 & 3 \\
$\mathbf{1 0}$ & 8 & 20 & 2 \\
$\mathbf{1 1}$ & 6 & 10 & 3 \\
\hline
\end{tabular}

Table 5 Results of final temperature $(\mathrm{t}=620 \mathrm{~s})$ for designed geometries

\begin{tabular}{cccc}
\hline Case & $\mathbf{P}=\mathbf{1 W}$ & $\mathbf{P}=\mathbf{2 W}$ & $\mathbf{P}=\mathbf{3 W}$ \\
\cline { 2 - 4 } $\mathbf{1}$ & 25.52701 & 26.05767 & \\
$\mathbf{2}$ & 25.74088 & 26.50567 & 26.58474 \\
$\mathbf{3}$ & 26.05708 & 27.14766 & 27.26295 \\
$\mathbf{4}$ & 25.68918 & 26.38428 & 28.22671 \\
$\mathbf{5}$ & 25.83996 & 26.11025 & 27.07537 \\
$\mathbf{6}$ & 25.75795 & 26.69111 & 26.66800 \\
$\mathbf{7}$ & 25.62041 & 26.52071 & 27.53490 \\
$\mathbf{8}$ & 25.51977 & 26.24666 & 27.27858 \\
$\mathbf{9}$ & 25.95494 & 26.04184 & 26.86830 \\
$\mathbf{1 0}$ & 25.64296 & 26.92147 & 26.56050 \\
$\mathbf{1 1}$ & 25.54928 & 26.29494 & 27.88059 \\
\end{tabular}

Table 6 Optimized geometry proposed by RSM

\begin{tabular}{ccccl}
\hline Number & A & B & C & \\
\hline $\mathbf{1}$ & $\mathbf{8}$ & $\mathbf{2 0}$ & $\mathbf{4}$ & Selected \\
$\mathbf{2}$ & 8 & 19.64 & 3.89 & \\
$\mathbf{3}$ & 6 & 19.83 & 3.17 & \\
$\mathbf{4}$ & 8 & 18.84 & 2.63 & \\
$\mathbf{5}$ & 8 & 19.06 & 2.51 & \\
\hline
\end{tabular}



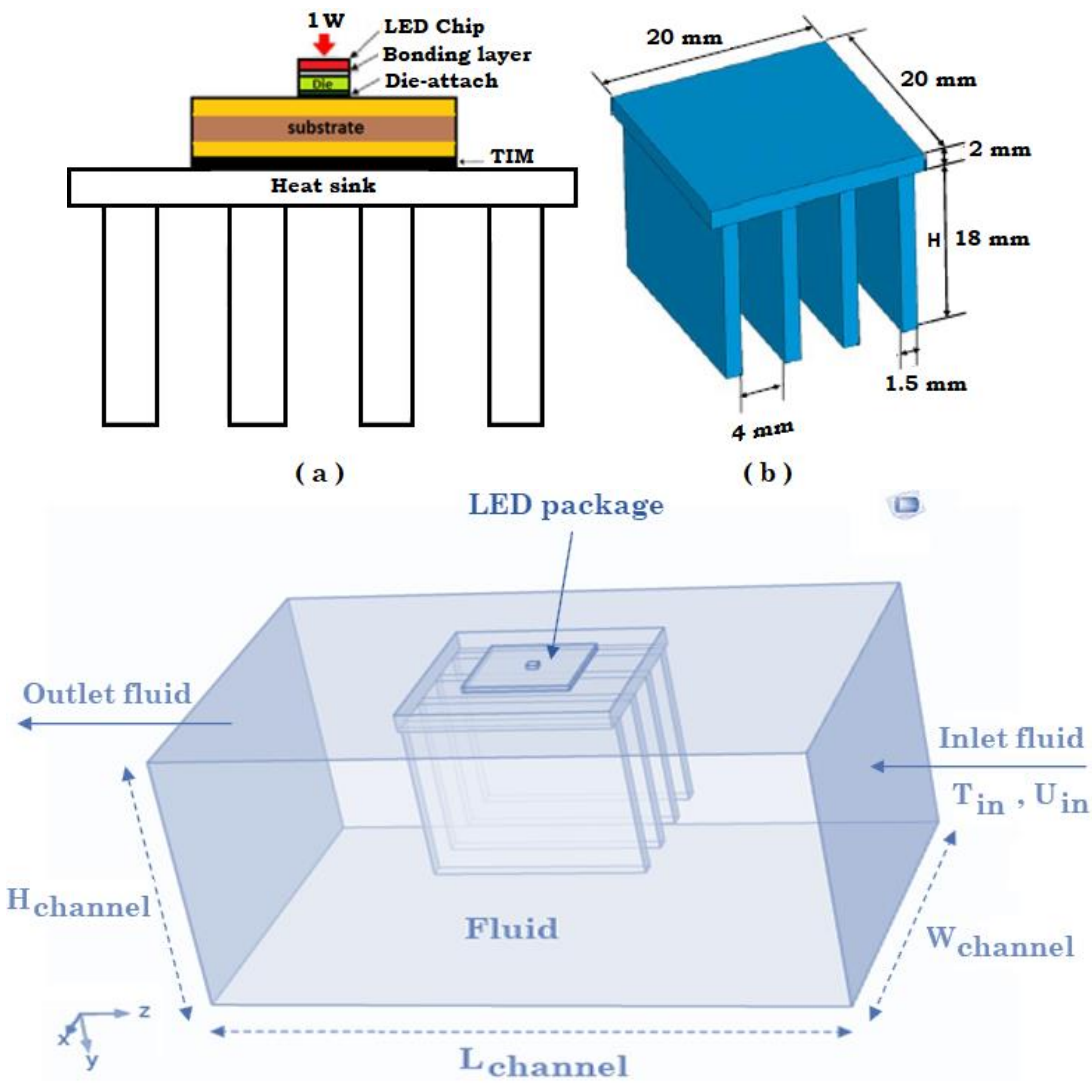

(c)

Fig. 1 (a) Structure of the LED package; (b) Sample Dimensions of heat sink, (c) Geometry of LED cooling by finned micro-channel filled by nanofluid 


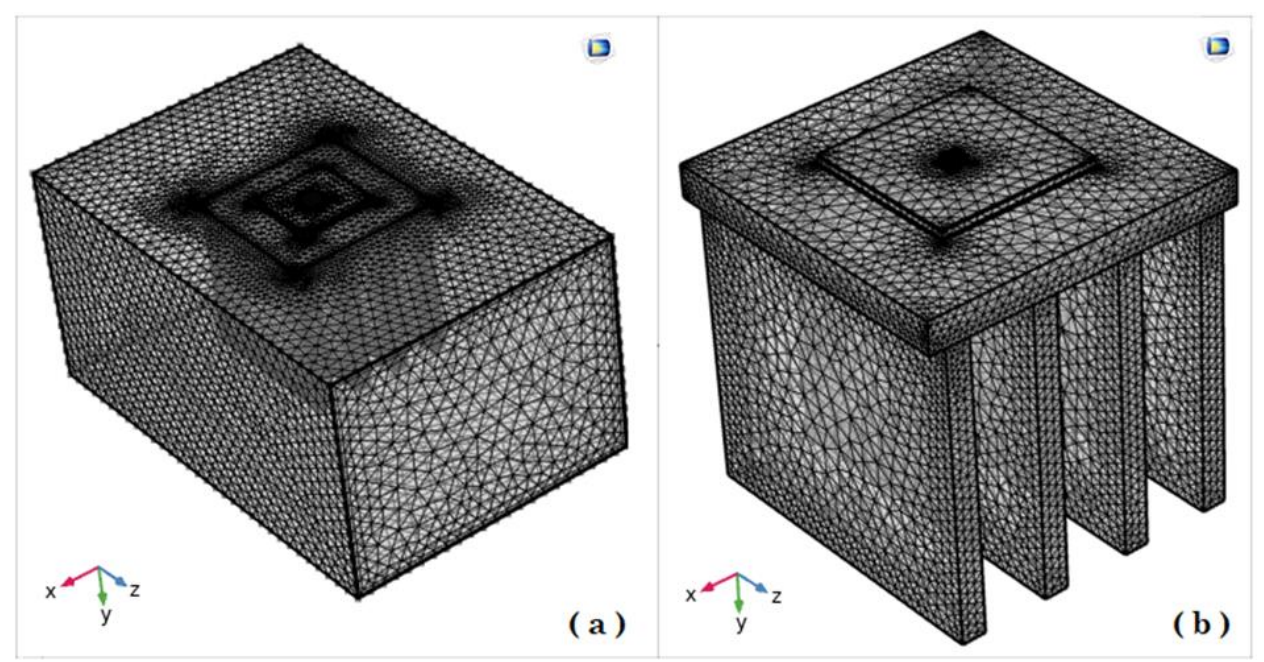

Fig. 2 Mesh generated in the domain and LED finned section 


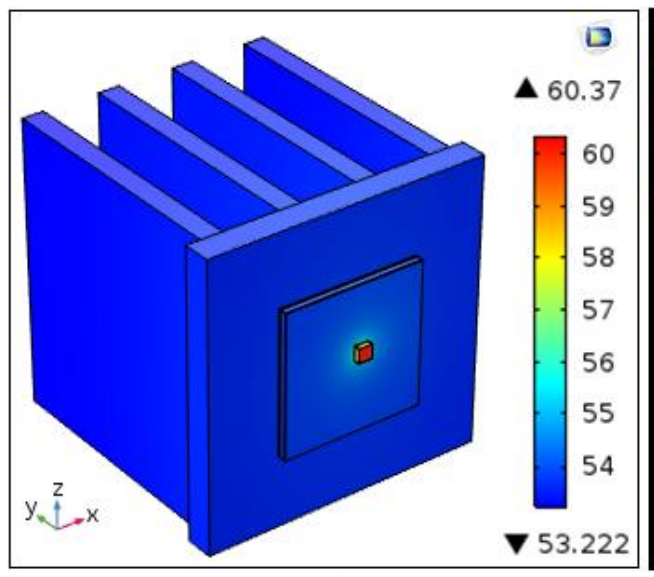

( a )

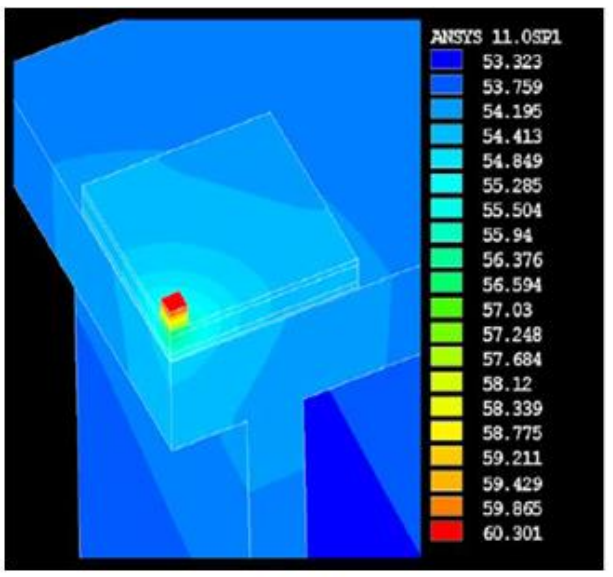

( b )

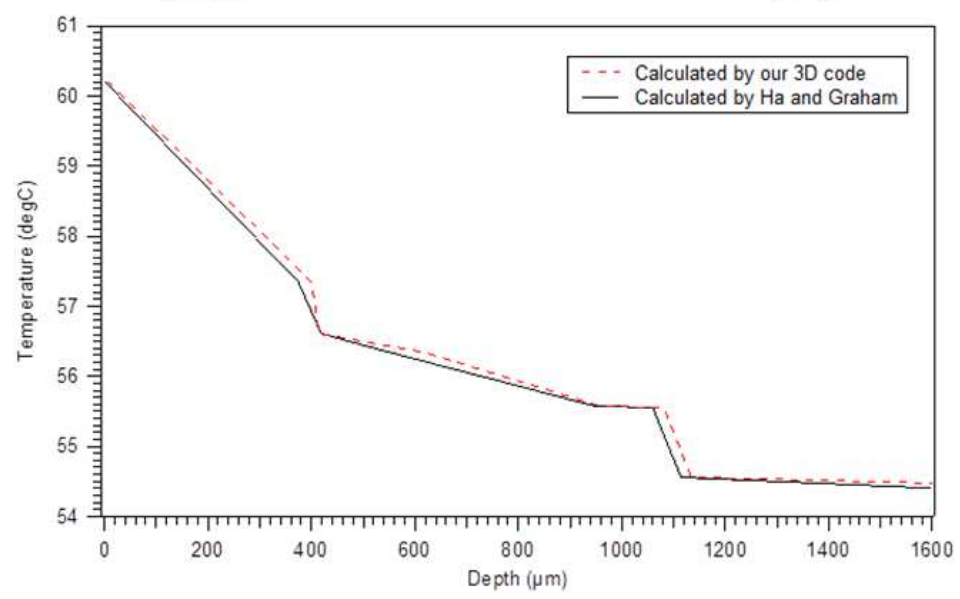

(c)

Fig. 3 Temperature distribution of the LED package: (a): Our 3D code (b): Ha and Graham code [7] (c), Comparison of vertical temperature profile along the center line (z axis) [8]. 


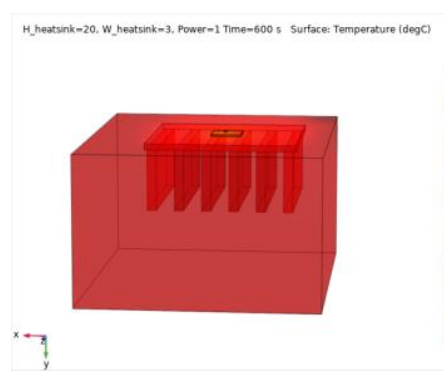

Case 1

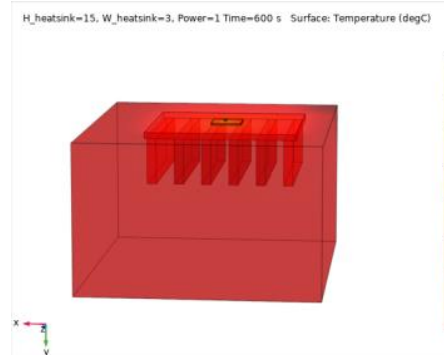

Case 4

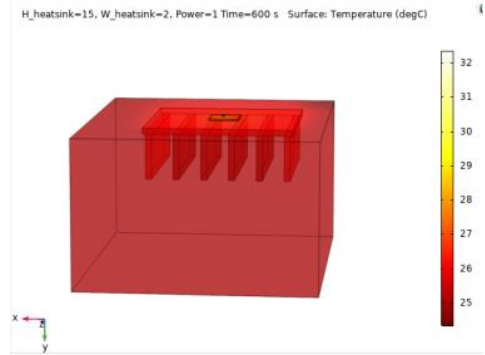

Case 7

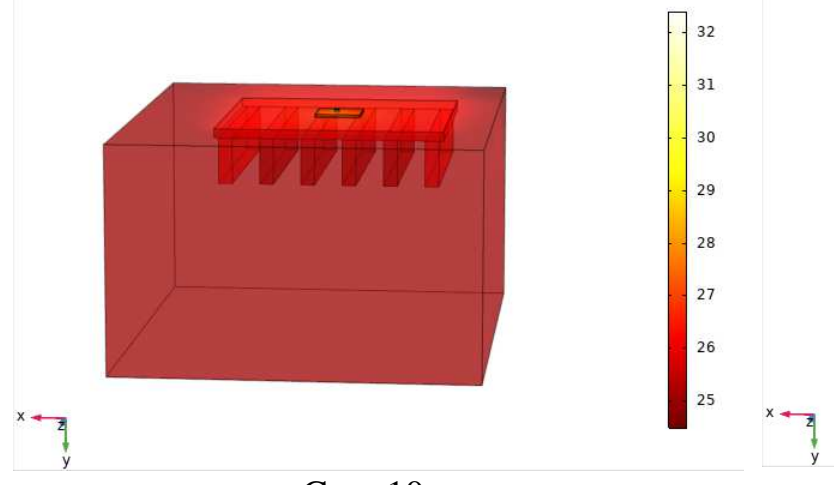

Case 10

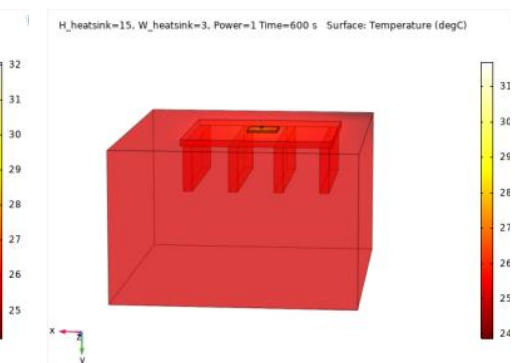

Case 2

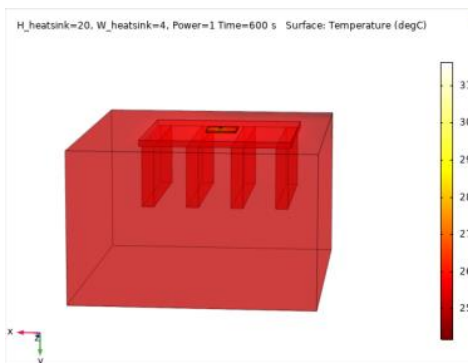

Case 5

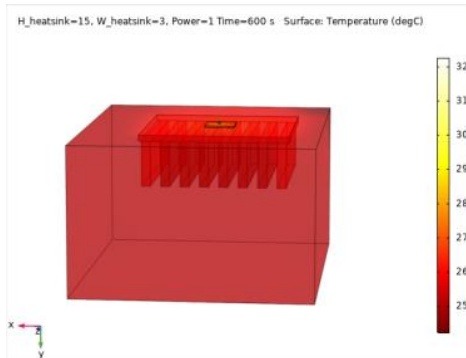

Case 8

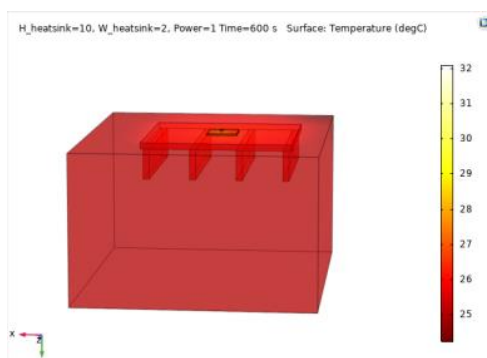

Case 3

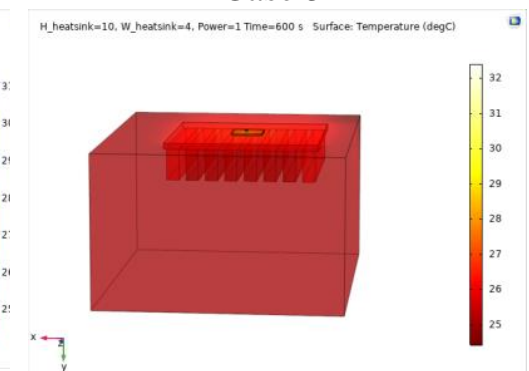

Case 6

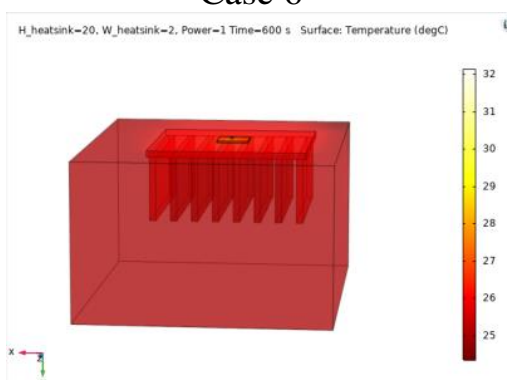

Case 9

H_heatsink $=15$, W_heatsink $=4$, Power $=1$ Time $=600$ s Surface: Temperature $(\operatorname{deg} \mathrm{C})$

Fig. 4 Temperature contours for the finned micro-channel of different geometries (11 Cases) 


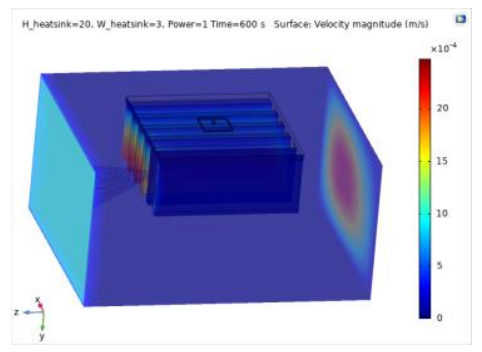

Case 1

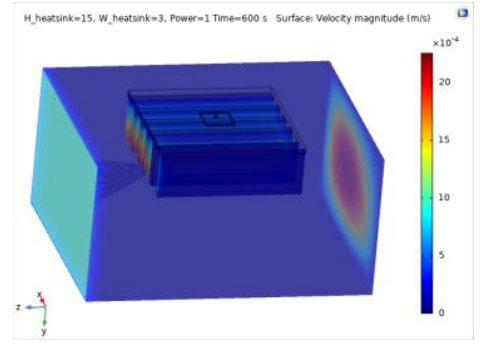

Case 4

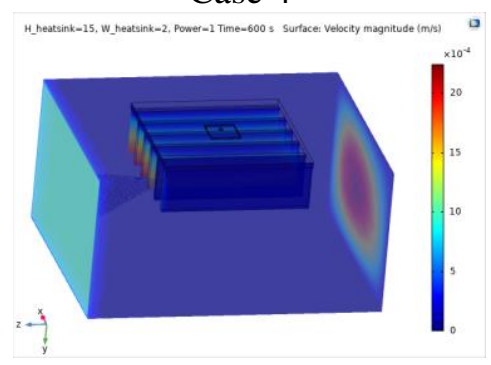

Case 7

H_heatsink $=10$, W_heatsink $=3$, Power $=1$ Time $=600$ s Surface: Velocity magnitude $(\mathrm{m} / \mathrm{s})$

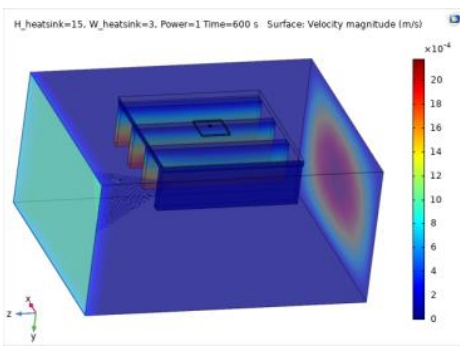

Case 2

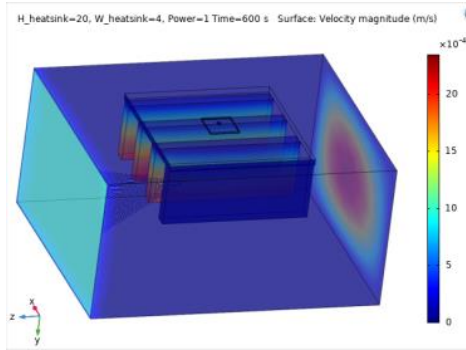

Case 5

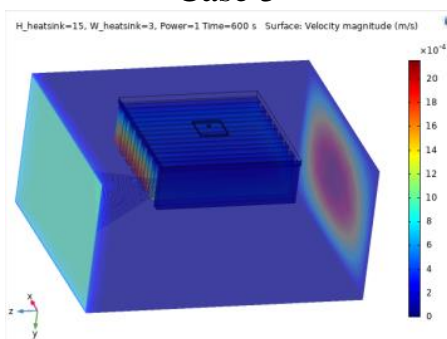

Case 8

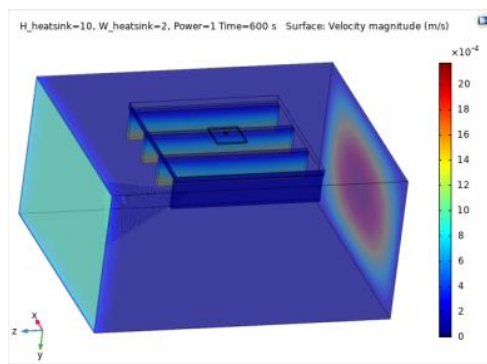

Case 3

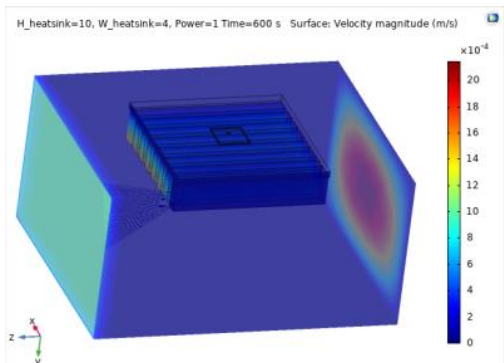

Case 6

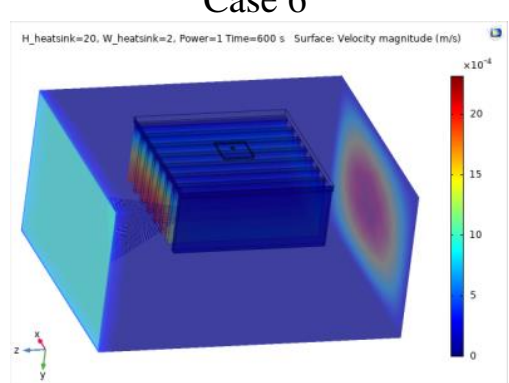

Case 9

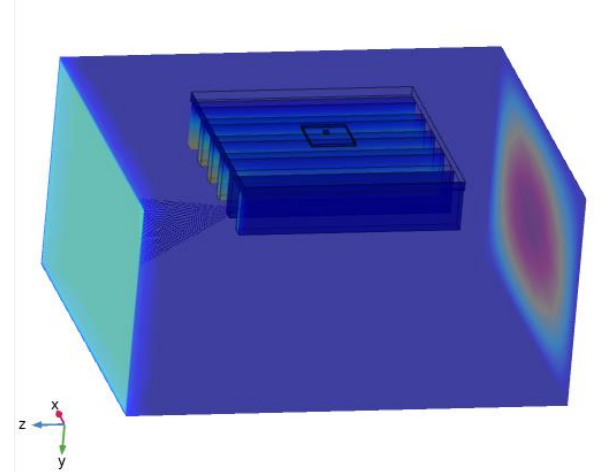

Case 10

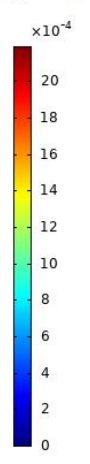

s

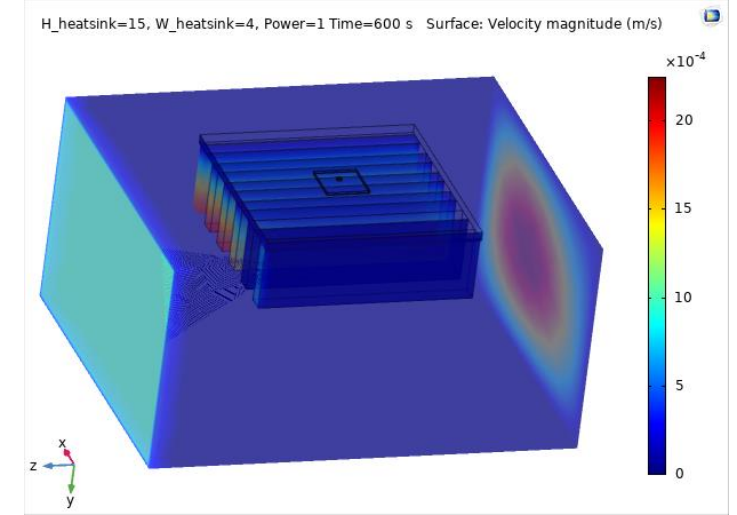

Case 11

Fig. 5 Velocity contours for the finned micro-channel of different geometries (11 Cases) 


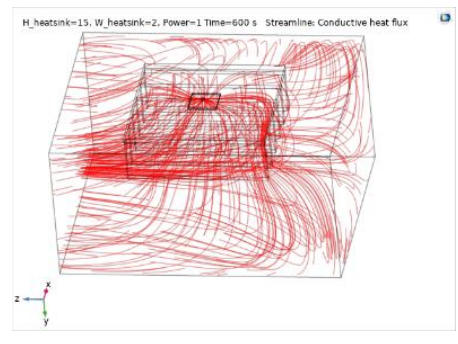

Case 1

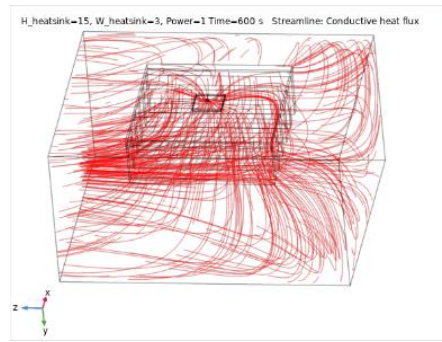

Case 4

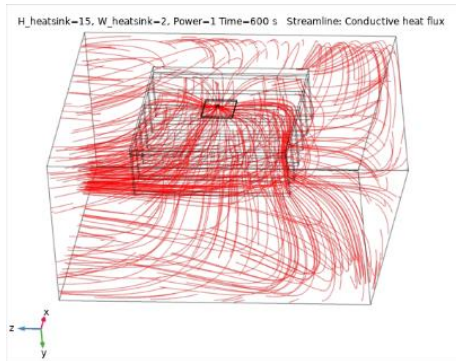

Case 7

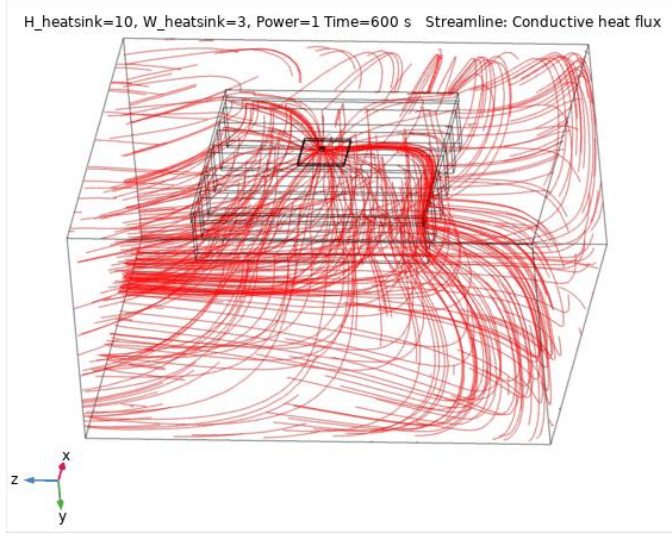

Case 10

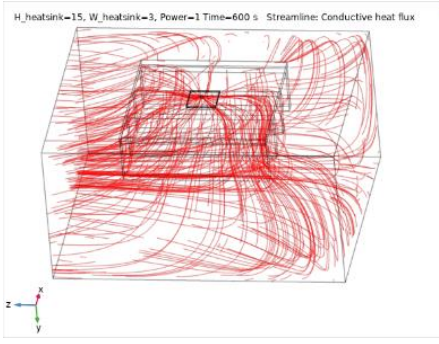

Case 2

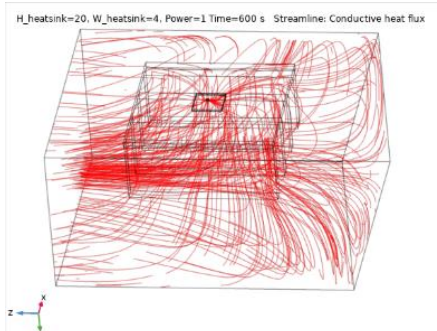

Case 5

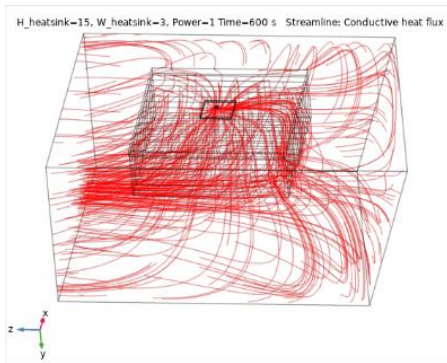

Case 8

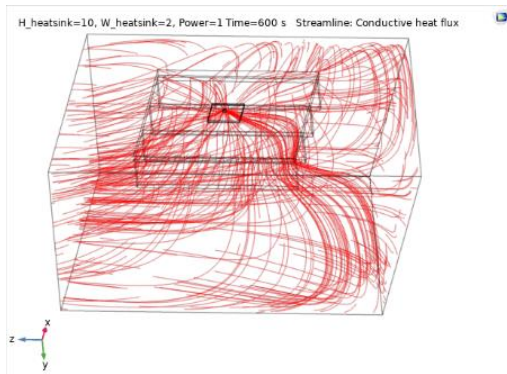

Case 3

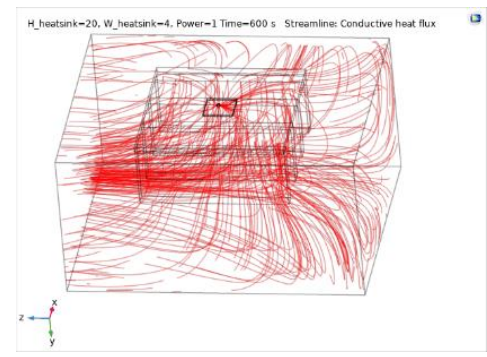

Case 6

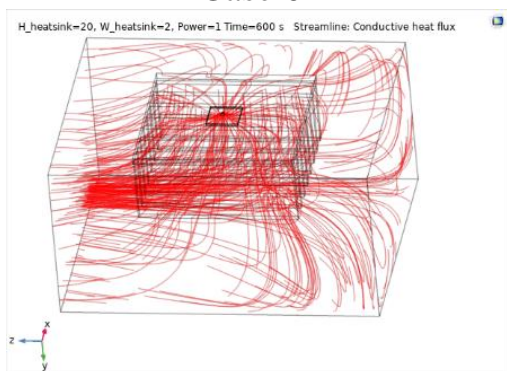

Case 9

- H_heatsink $=15$, W $_{\text {heatsink }}=4$, Power $=1$ Time $=600 \mathrm{~s}$ Streamline: Conductive heat flux

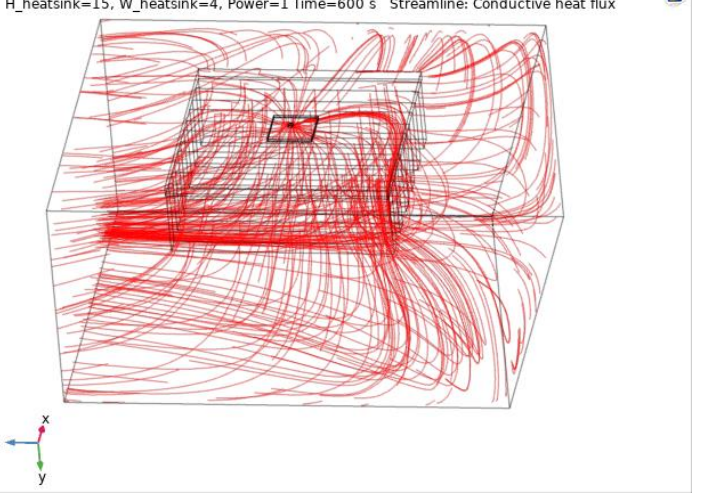

Case 11

Fig. 6 Streamline contours for the finned micro-channel of different geometries (11 Cases) 


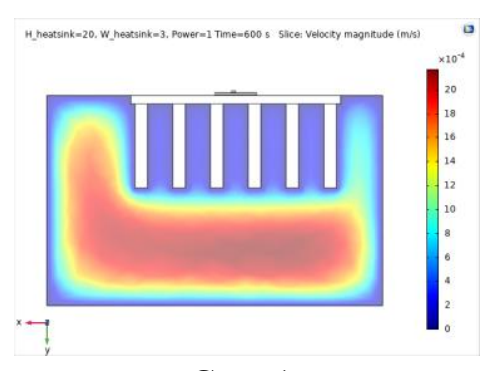

Case 1

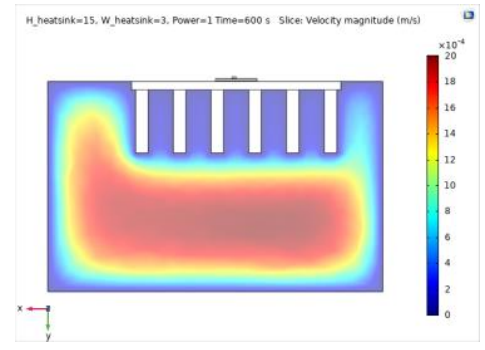

Case 4

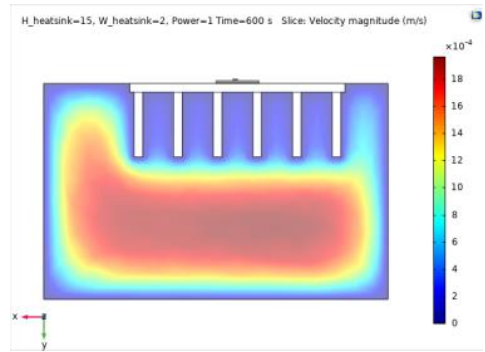

Case 7

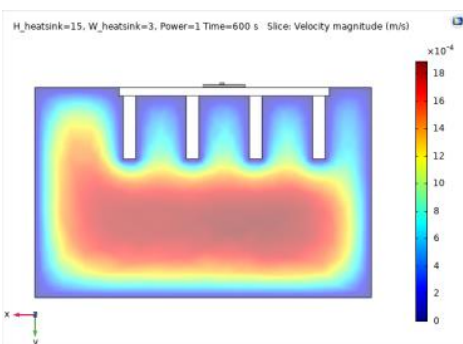

Case 2

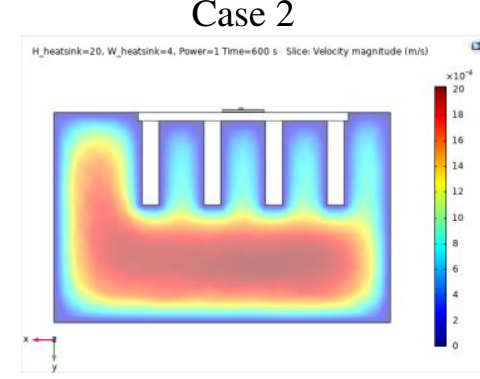

Case 5

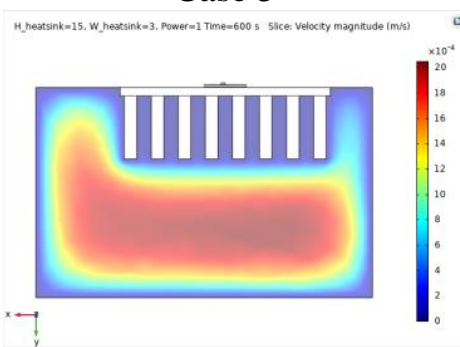

Case 8

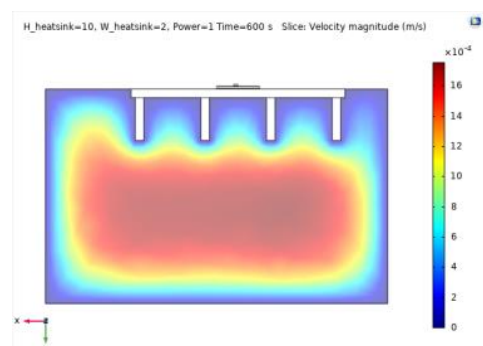

Case 3

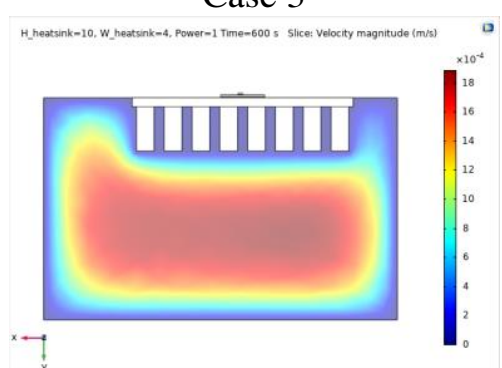

Case 6

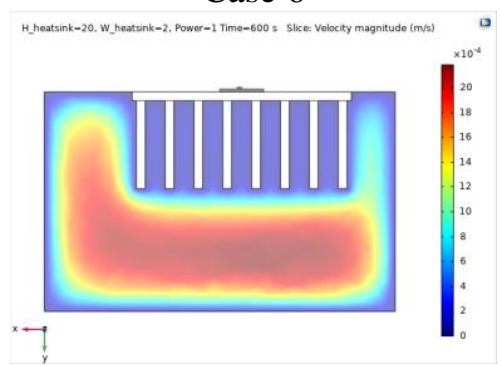

Case 9

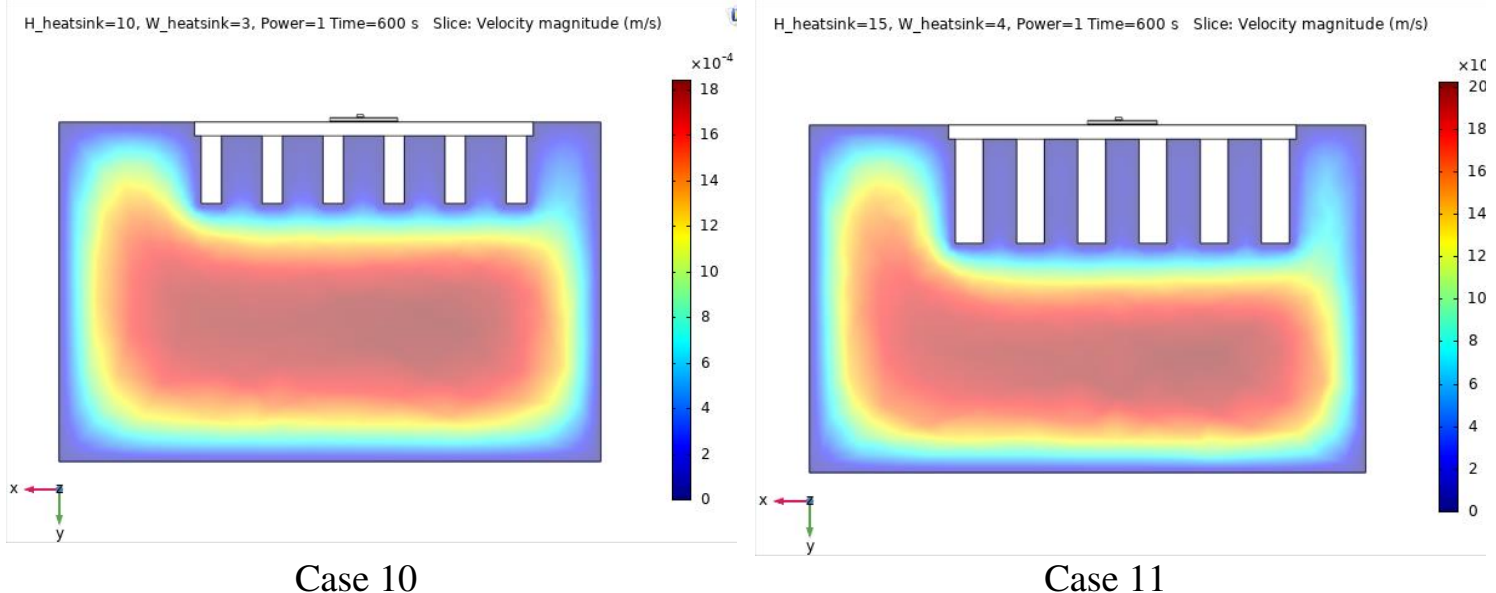

Fig. 7 2D Velocity contours for the finned micro-channel of different geometries (11 Cases) 


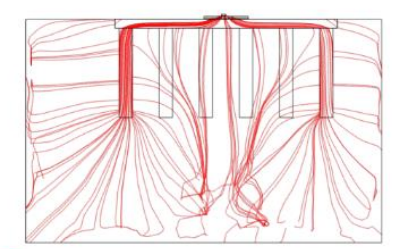

$x \longrightarrow$

Case 1
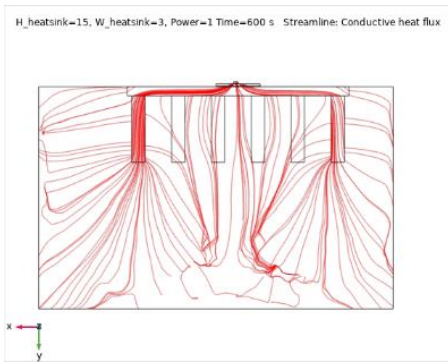

Case 4
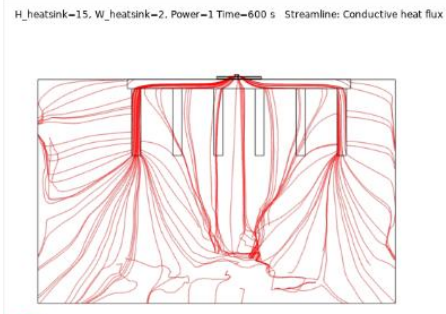

$\times ?$

Case 7

H_heatsink $=10$, W_heatsink $=3$, Power $=1$ Time $=600$ s Streamline: Conductive heat flux

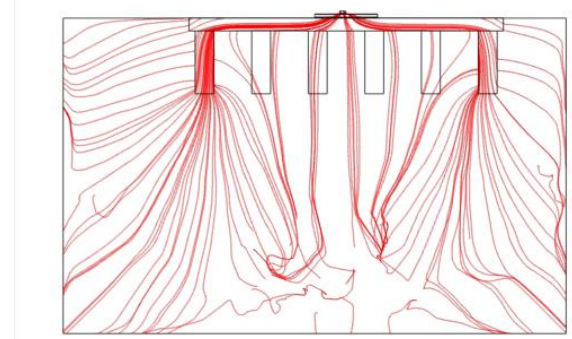

$x \longleftarrow$

Case 10

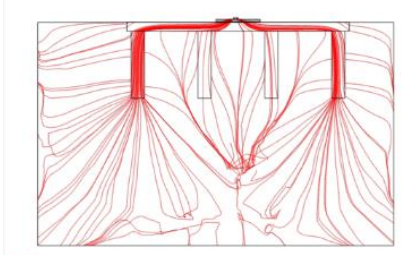

Case 2

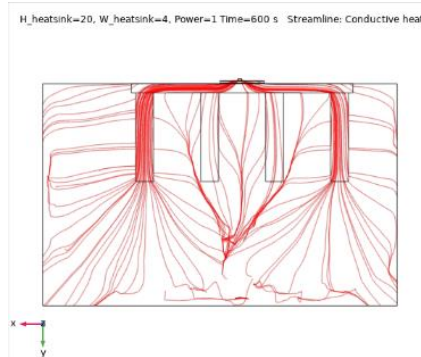

Case 5

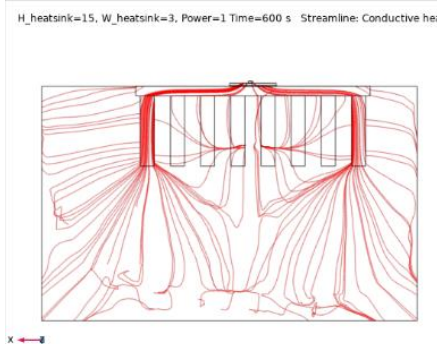

Case 8

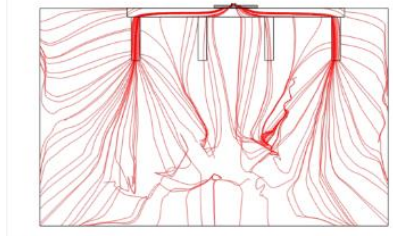

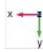
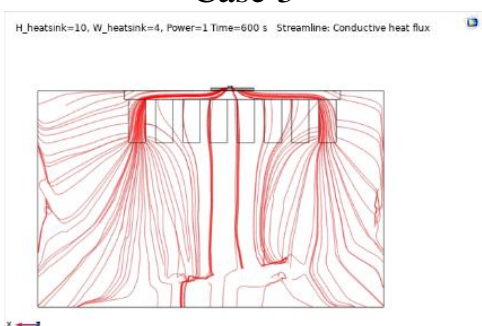

$\times \rightarrow$
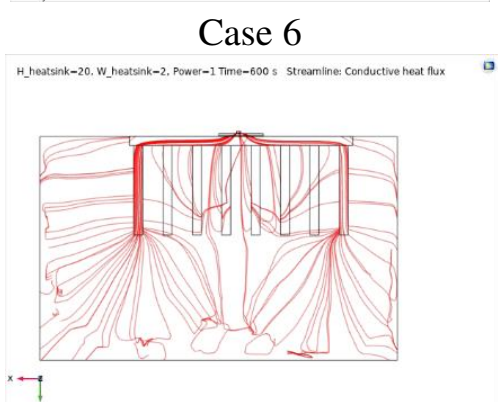

Case 9 H_heatsink $=15$, W_heatsink $=4$, Power $=1$ Time $=600$ s Streamline: Conductive heat flux

Fig. 8 2D Streamline contours for the finned micro-channel of different geometries (11 Cases) 


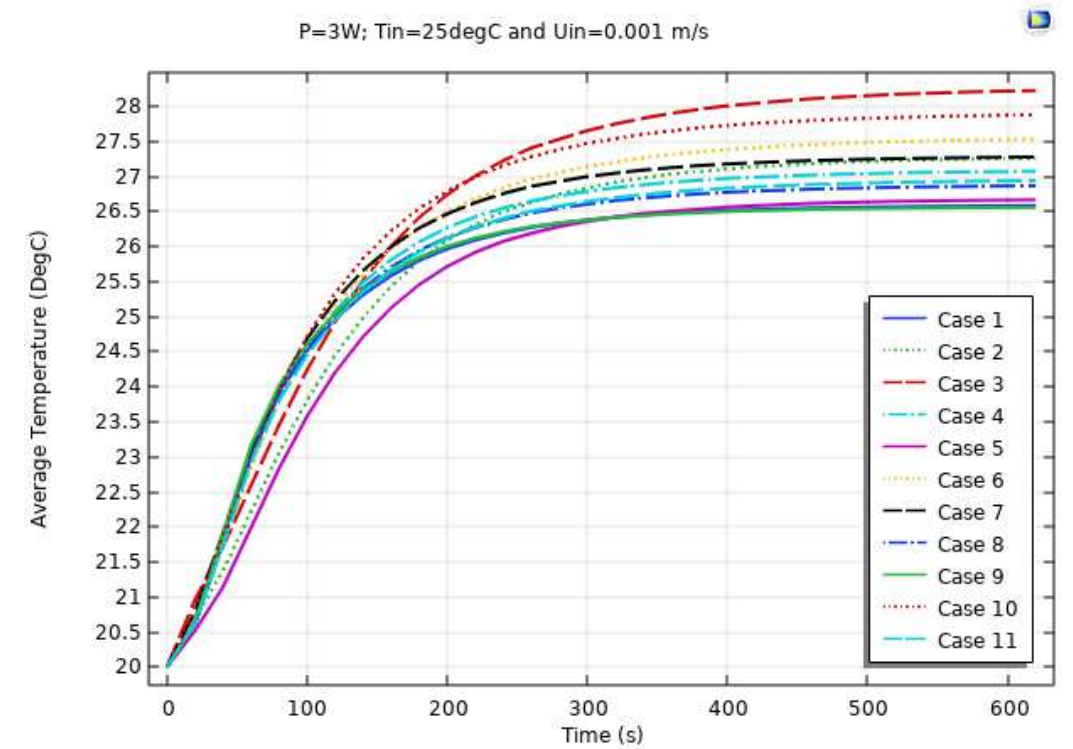

(a)

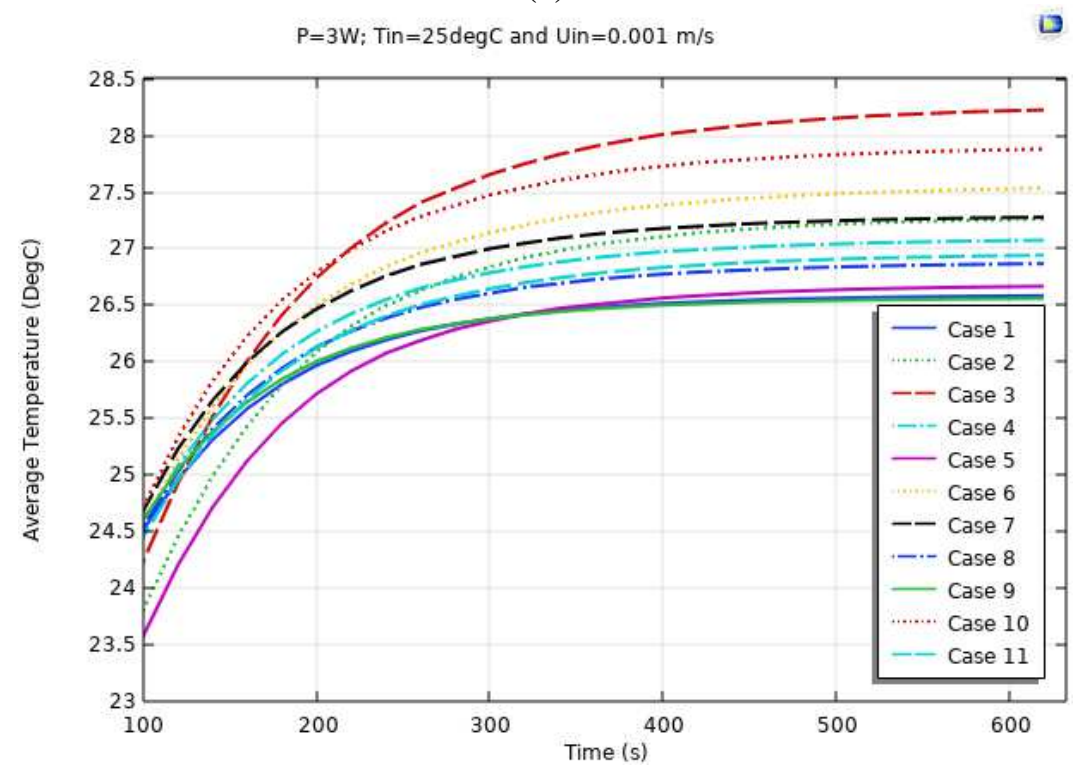

(b)

Fig. 9 Average Temp. when $\mathrm{P}=3 \mathrm{~W}$ for different 11 cases a) complete view, b) zoomed view 


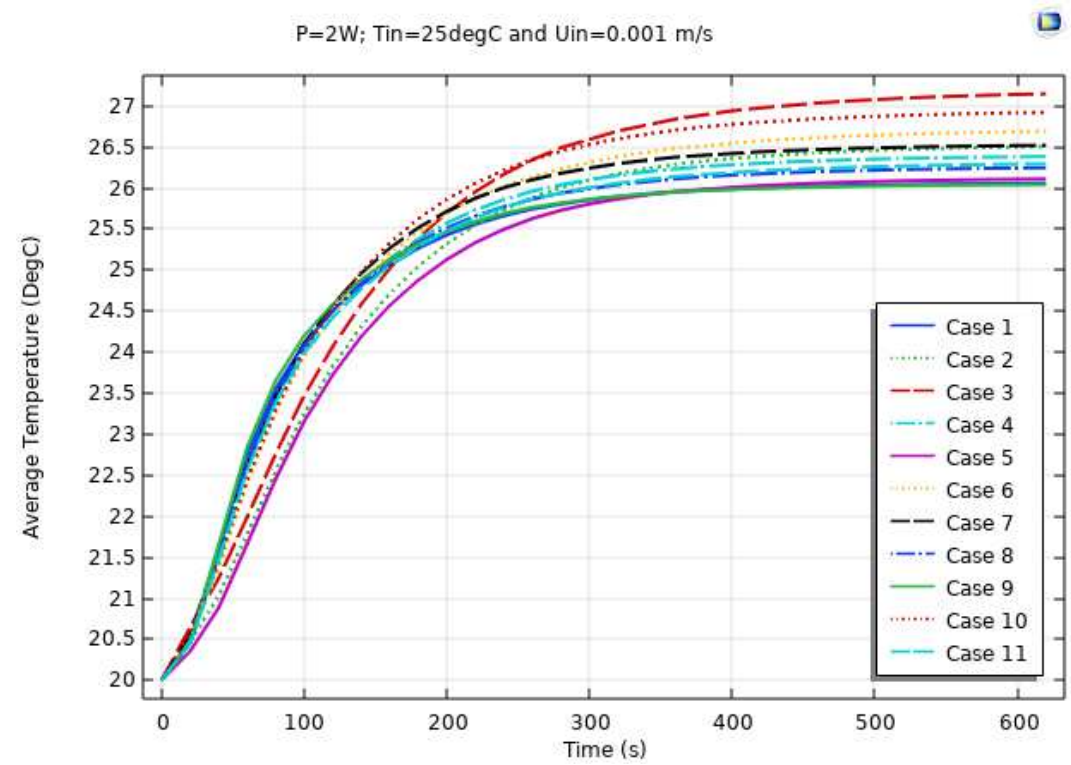

(a)

$\mathrm{P}=2 \mathrm{~W} ;$ Tin $=25 \operatorname{deg} \mathrm{C}$ and $\operatorname{Uin}=0.001 \mathrm{~m} / \mathrm{s}$

D

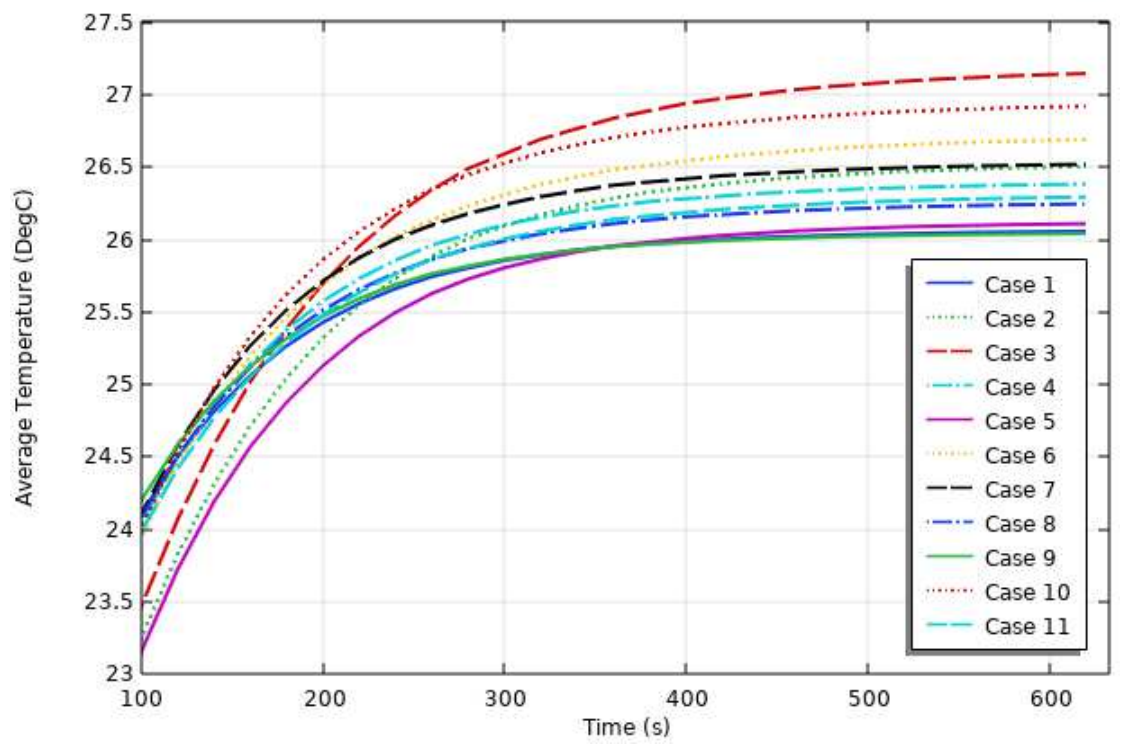

(b)

Fig. 10 Average Temp. when $\mathrm{P}=2 \mathrm{~W}$ for different 11 cases a) complete view, b) zoomed view 


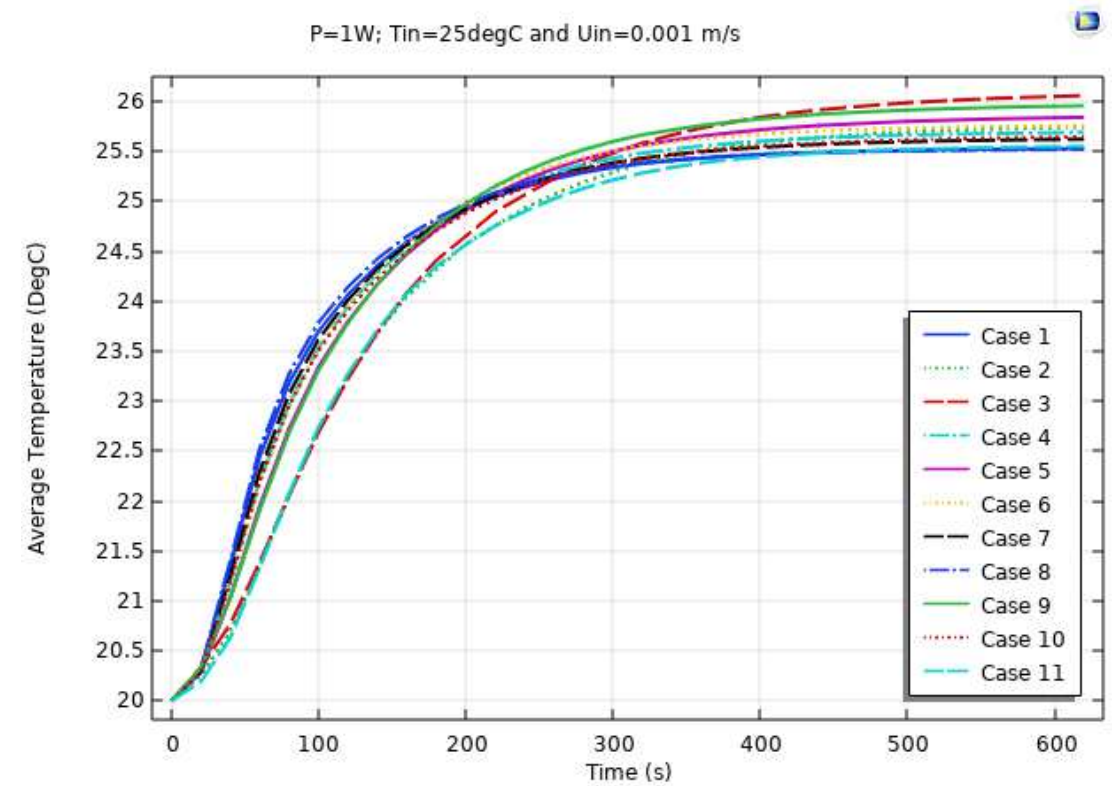

(a)

$\mathrm{P}=1 \mathrm{~W} ;$ Tin $=25 \operatorname{deg} \mathrm{C}$ and $\mathrm{Uin}=0.001 \mathrm{~m} / \mathrm{s}$

B

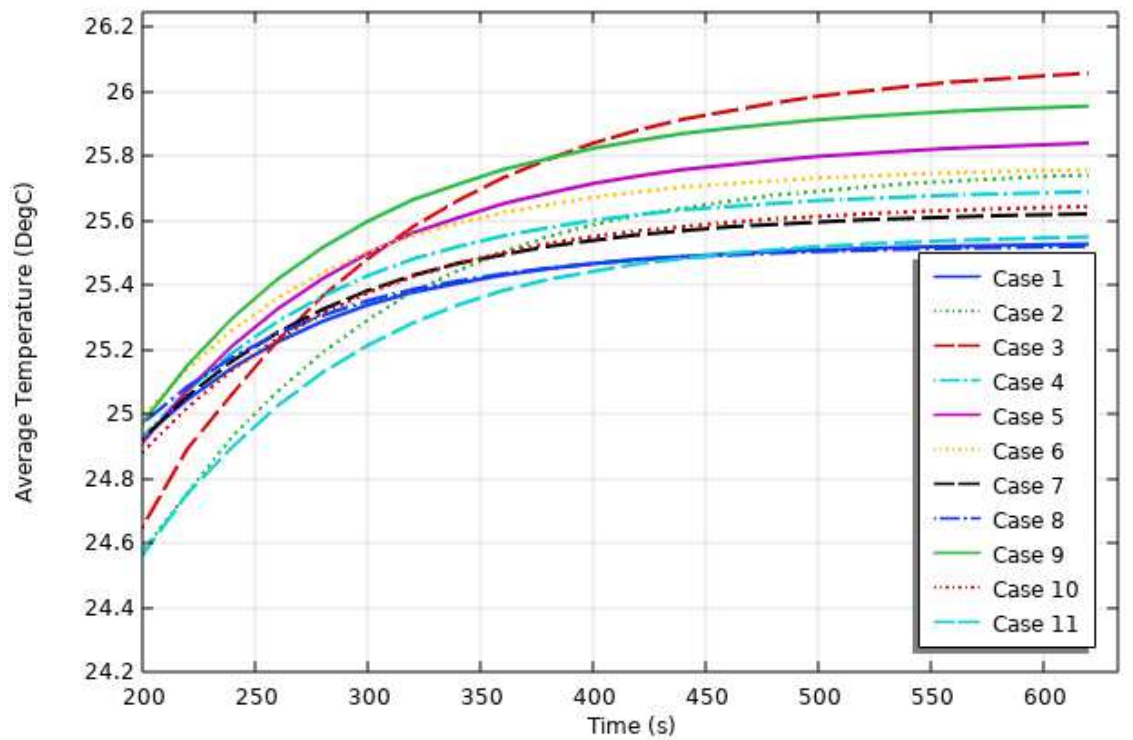

(b)

Fig. 11 Average Temp. when $\mathrm{P}=1 \mathrm{~W}$ for different 11 cases a) complete view, b) zoomed view 

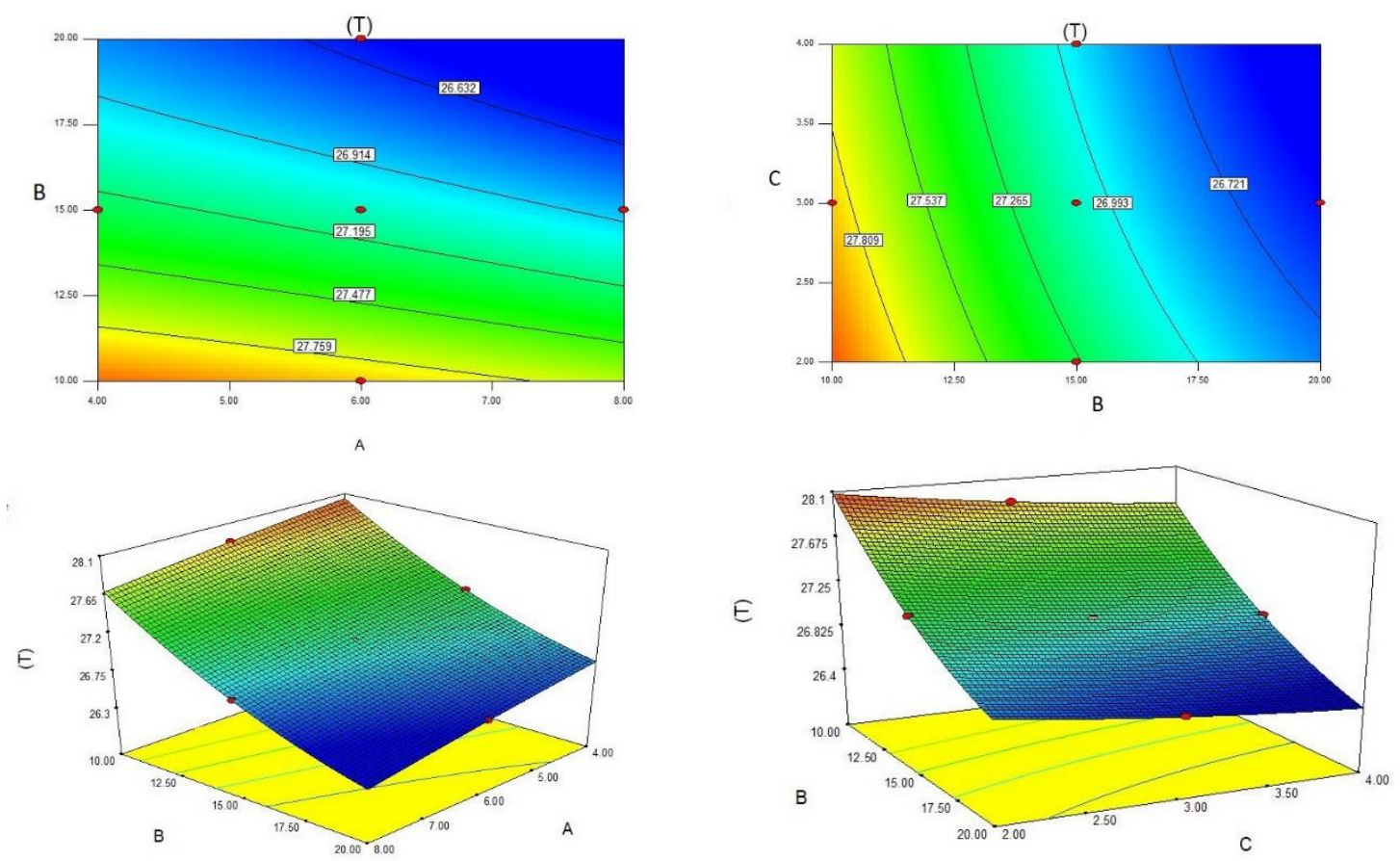

Fig. 12 2D and 3D contour of geometry parameters on temperature 


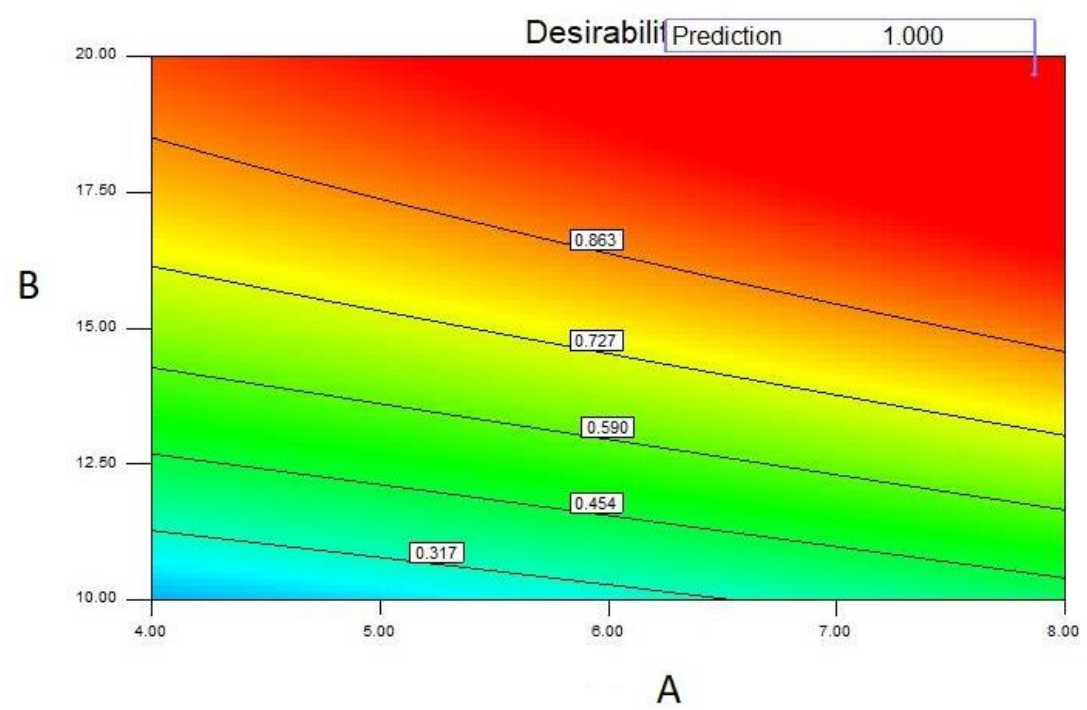

Fig. 13 Desirability function of optimized geometry 
$\square$

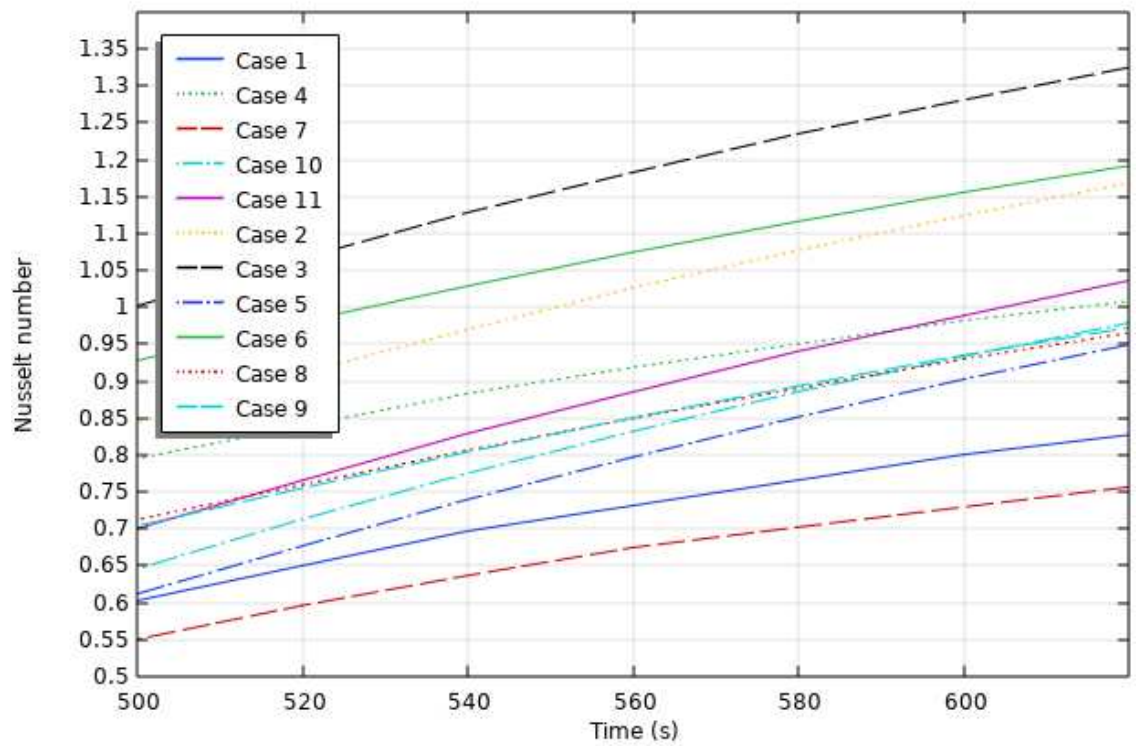

(a)

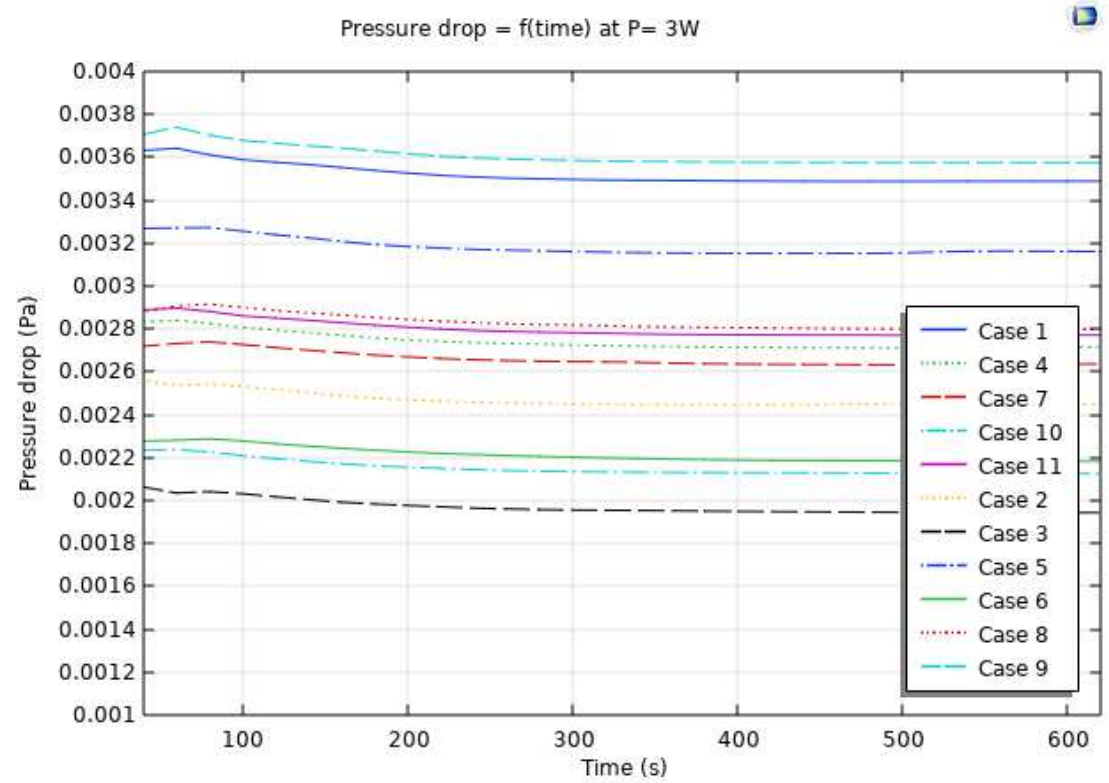

(b)

Fig. 14 a) Nusselt number b) Pressure drops graphs for $\mathrm{P}=3 \mathrm{~W}$ for all designed cases 

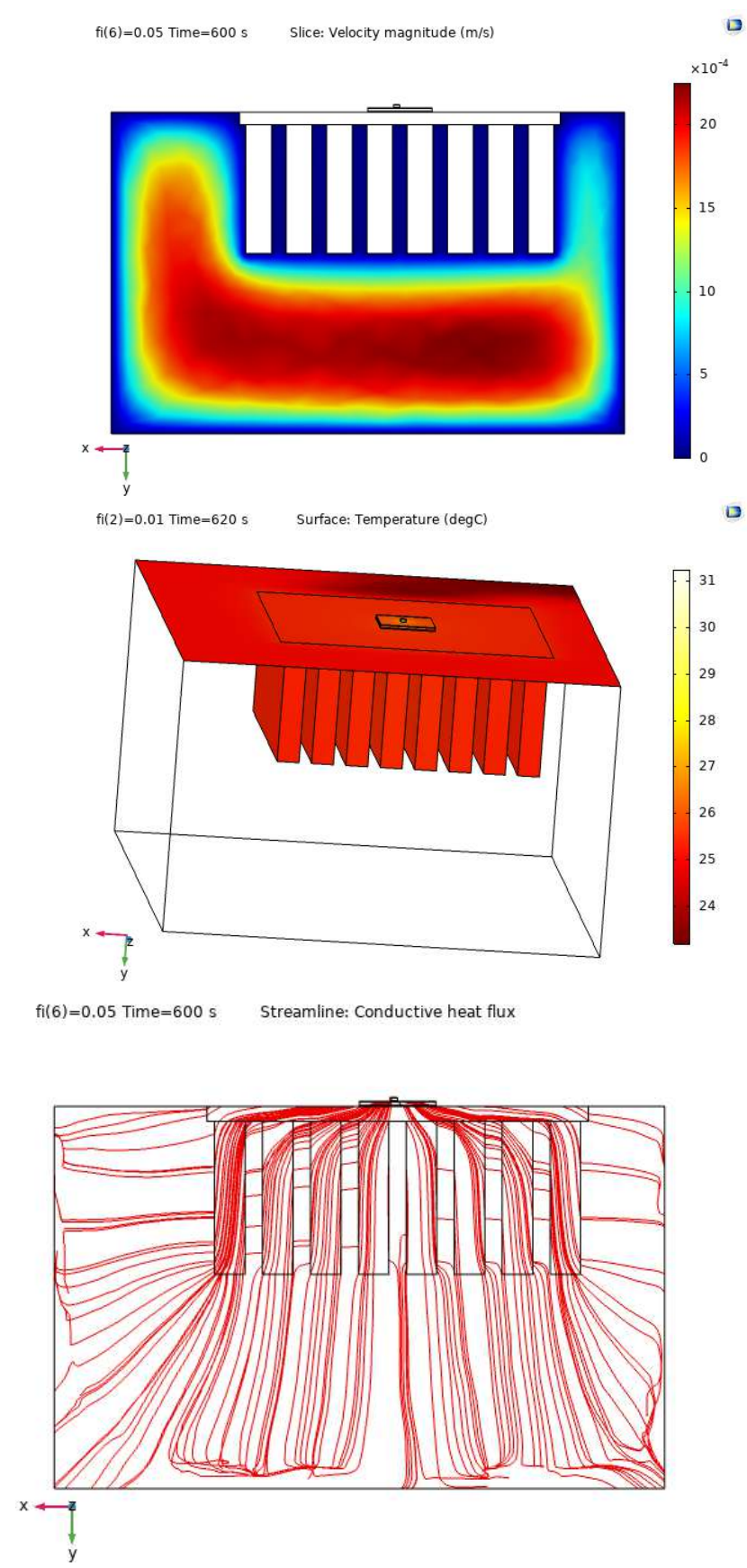

Fig. 15 Velocity, temperature and streamline for optimized case 

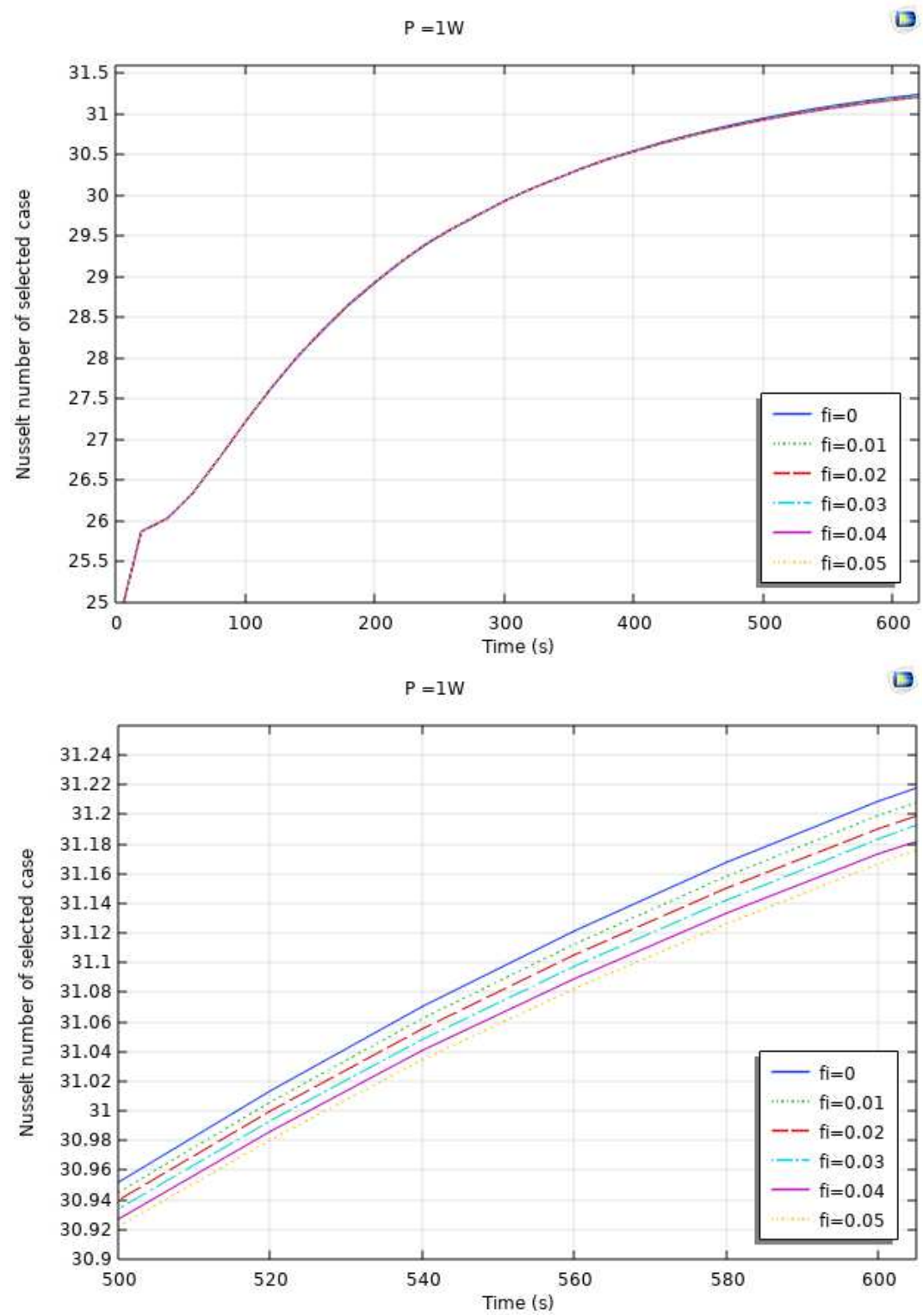

Fig. 16 Effect of different nanoparticles concentration on Nusselt number of the optimized case 


\section{Figures}
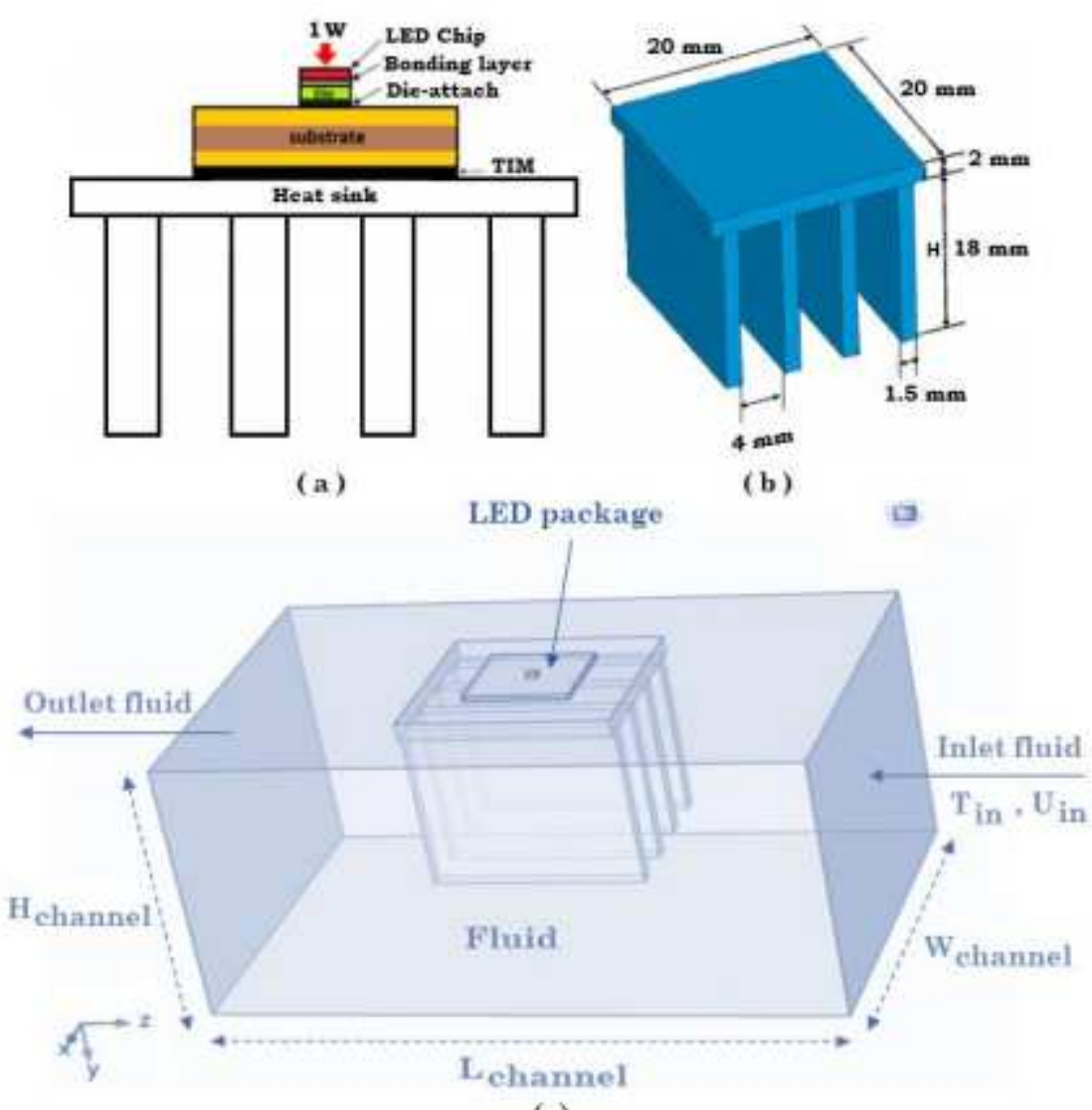

(c)

\section{Figure 1}

(a) Structure of the LED package; (b) Sample Dimensions of heat sink, (c) Geometry of LED cooling by finned micro-channel filled by nanofluid
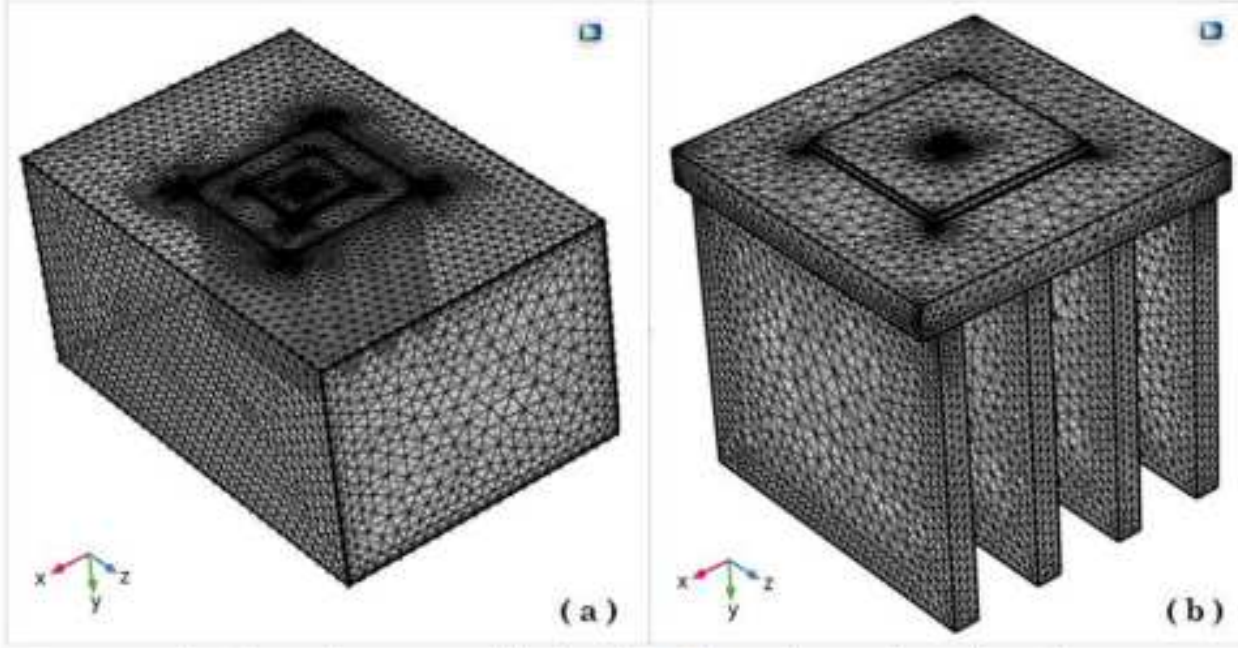

Figure 2 
Mesh generated in the domain and LED finned section

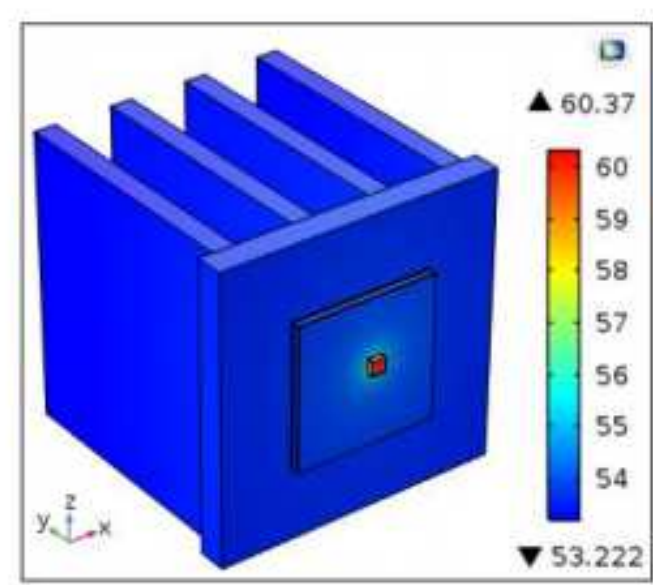

(a)

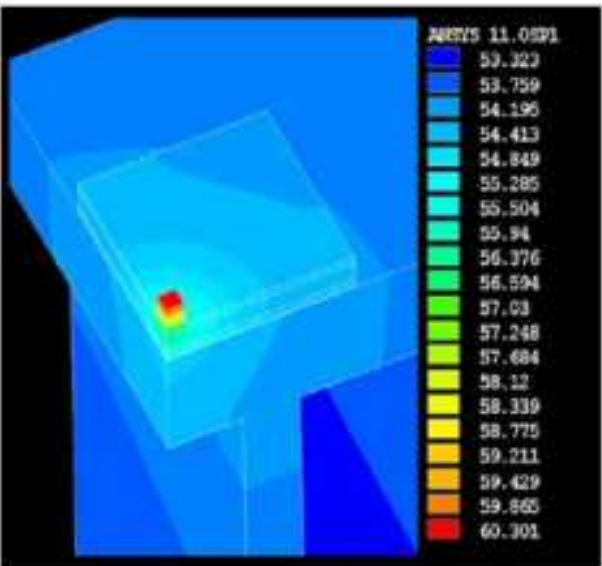

(b)

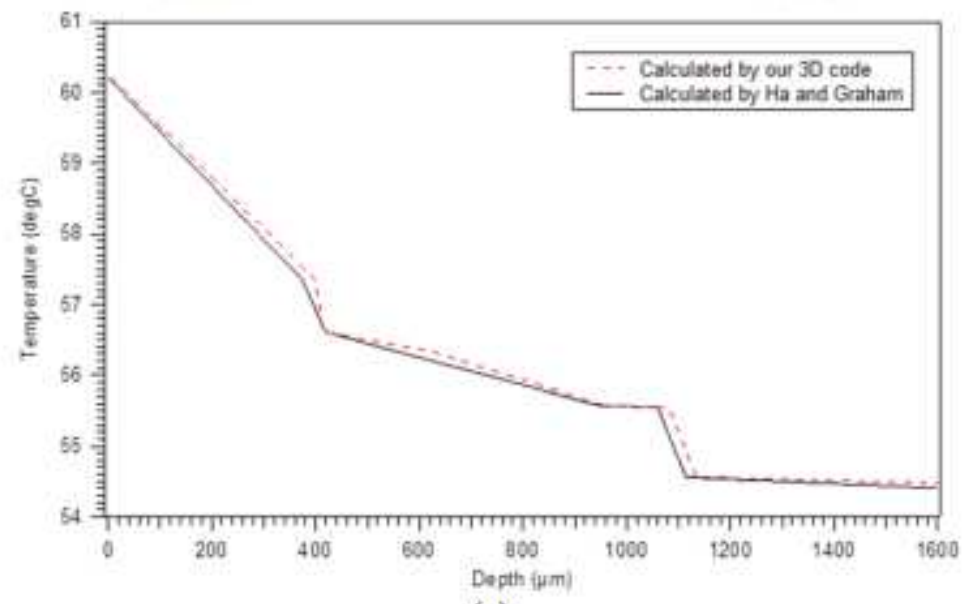

(c)

\section{Figure 3}

Temperature distribution of the LED package: (a): Our 3D code (b): Ha and Graham code [7] (c), Comparison of vertical temperature profile along the center line (z axis) [8]. 


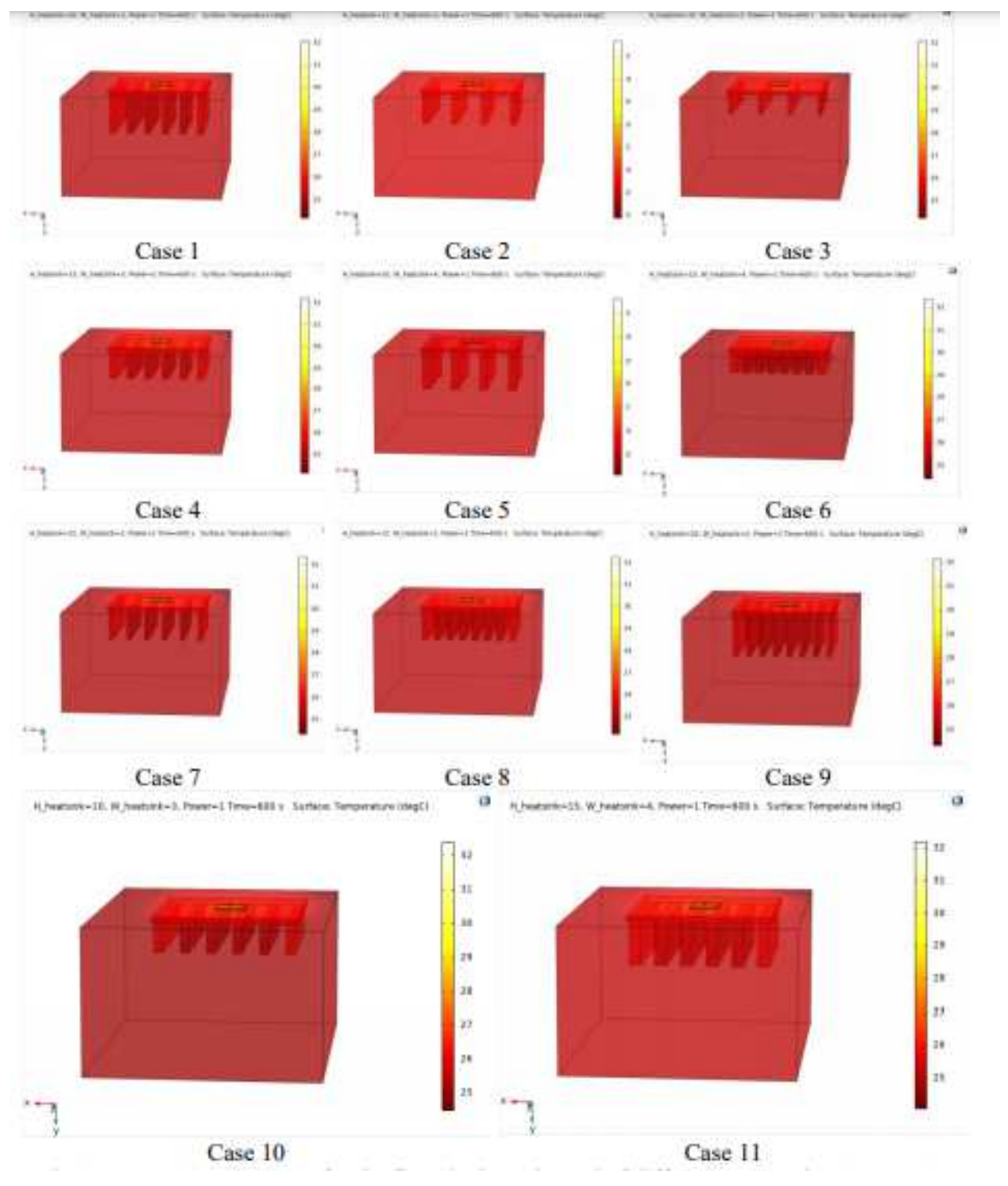

Figure 4

Temperature contours for the finned micro-channel of different geometries ( 11 Cases) 

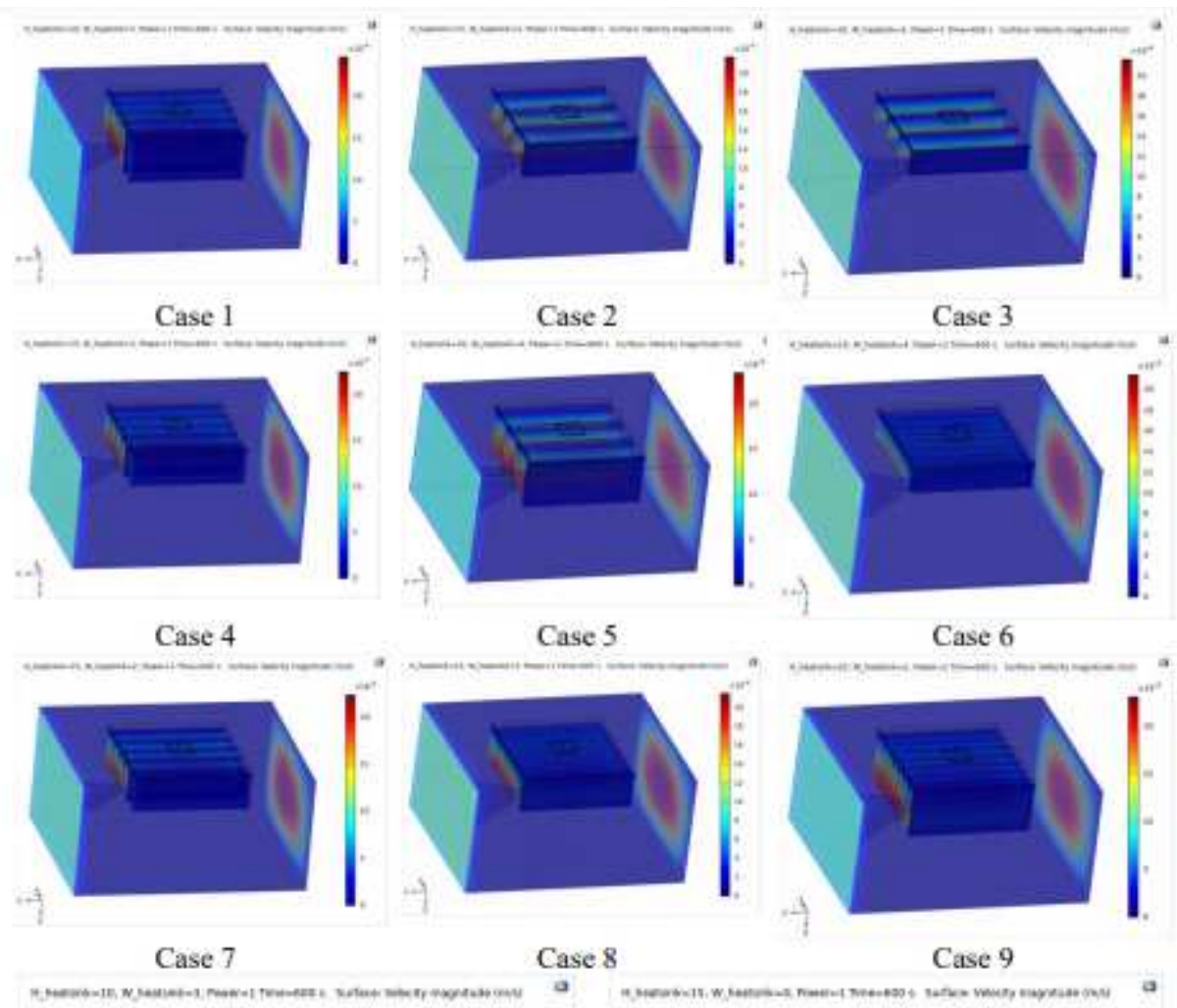

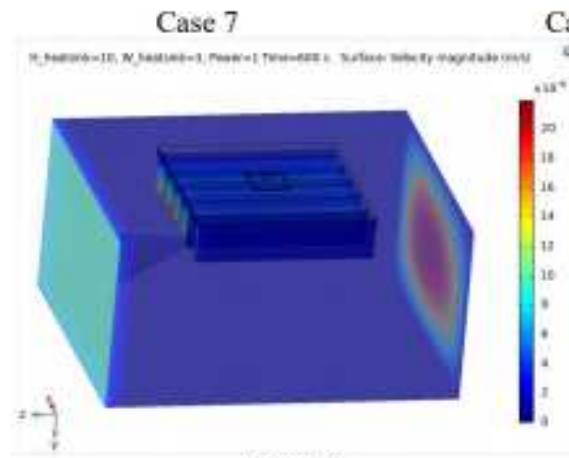

Case 10

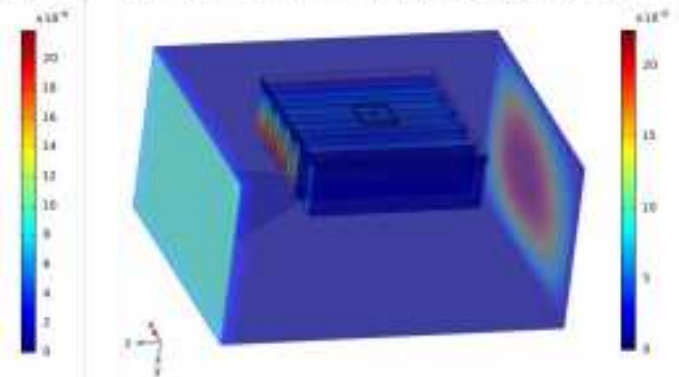

Case 11

Figure 5

Velocity contours for the finned micro-channel of different geometries (11 Cases) 

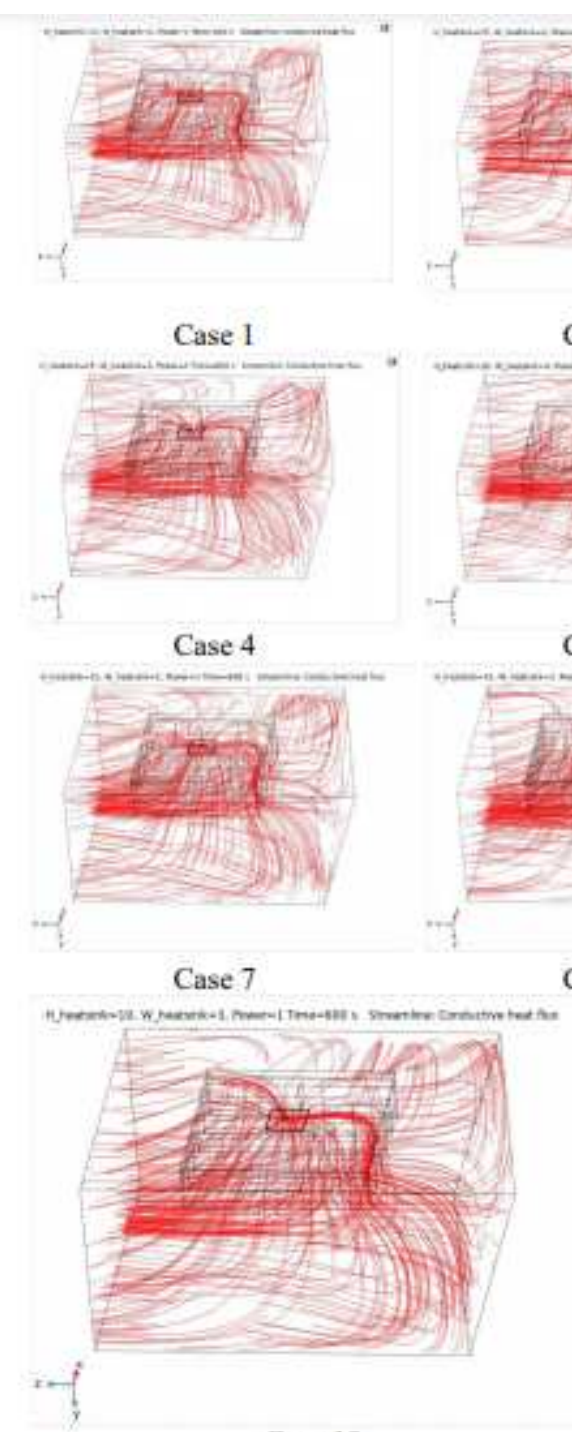

Case 10

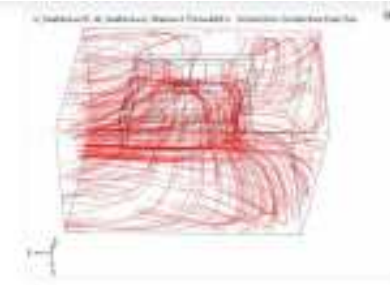

Case 2
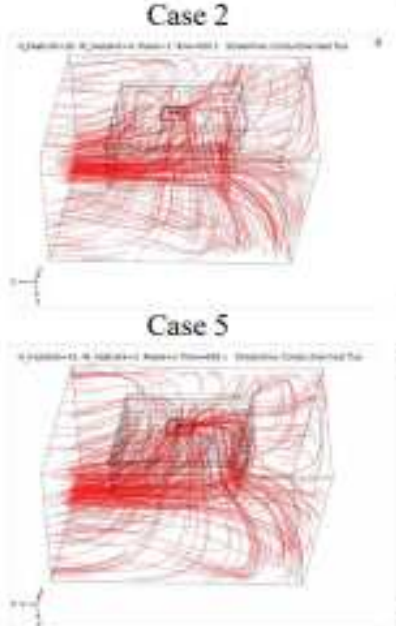

Case 8
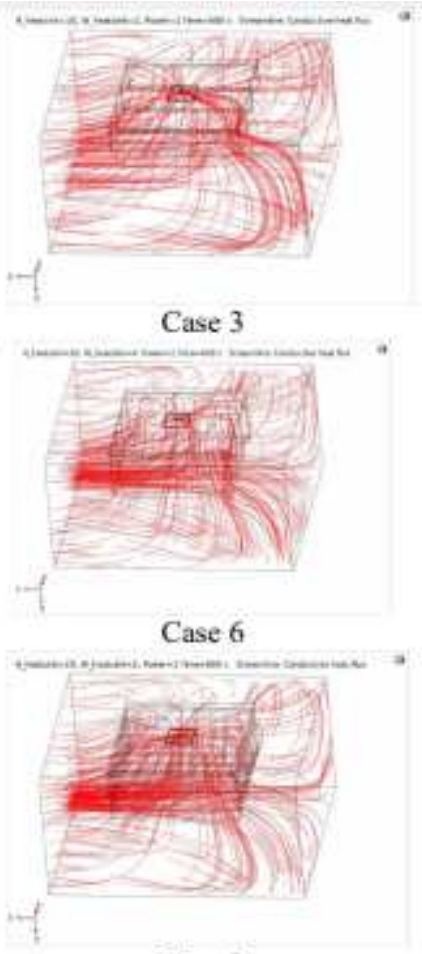

Case 9

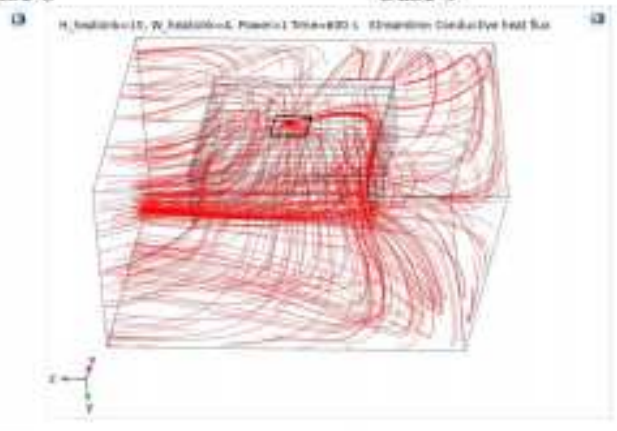

Case 11

Figure 6

Streamline contours for the finned micro-channel of different geometries (11 Cases) 


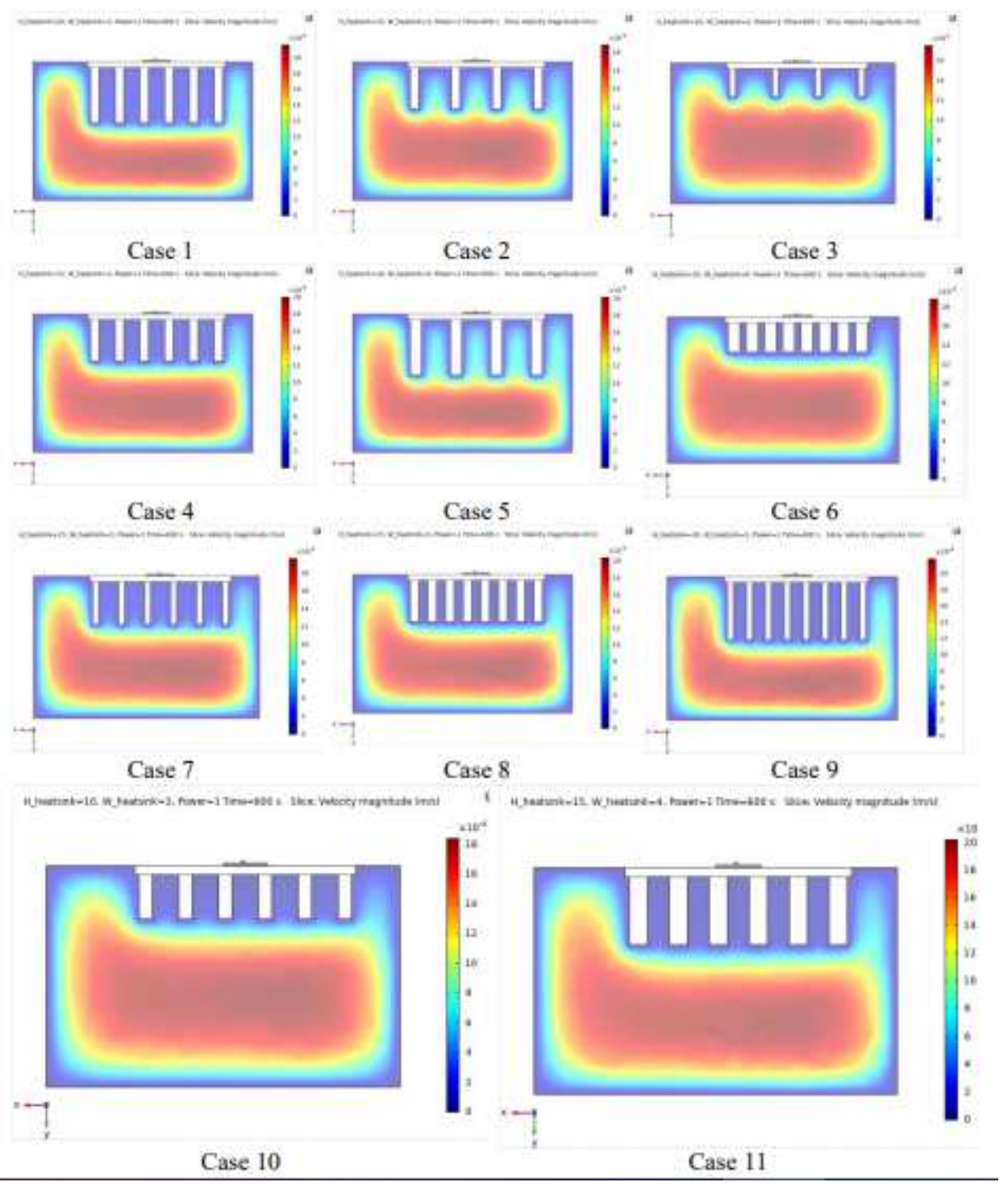

Figure 7

2D Velocity contours for the finned micro-channel of different geometries (11 Cases) 


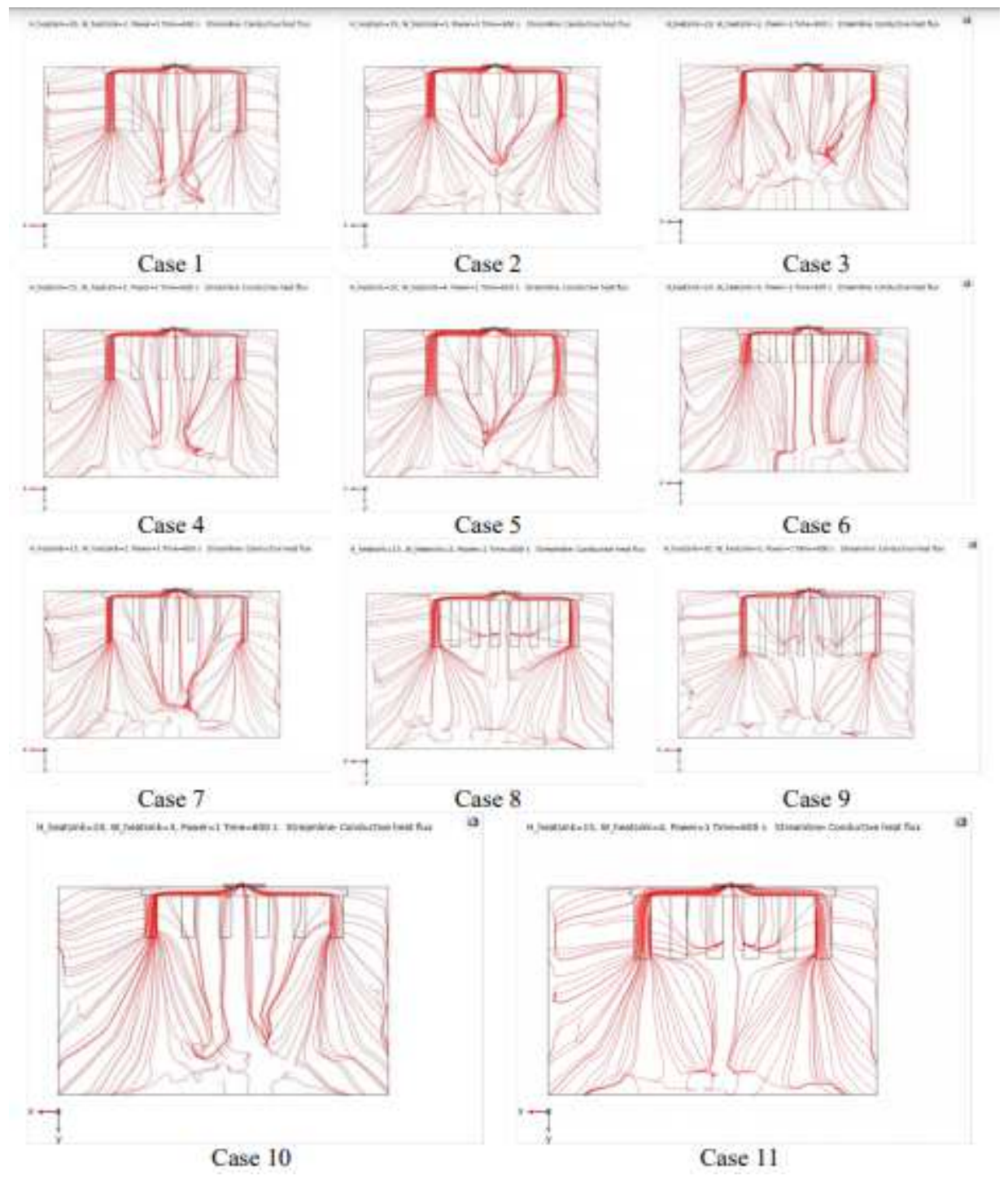

Figure 8

2D Streamline contours for the finned micro-channel of different geometries (11 Cases) 


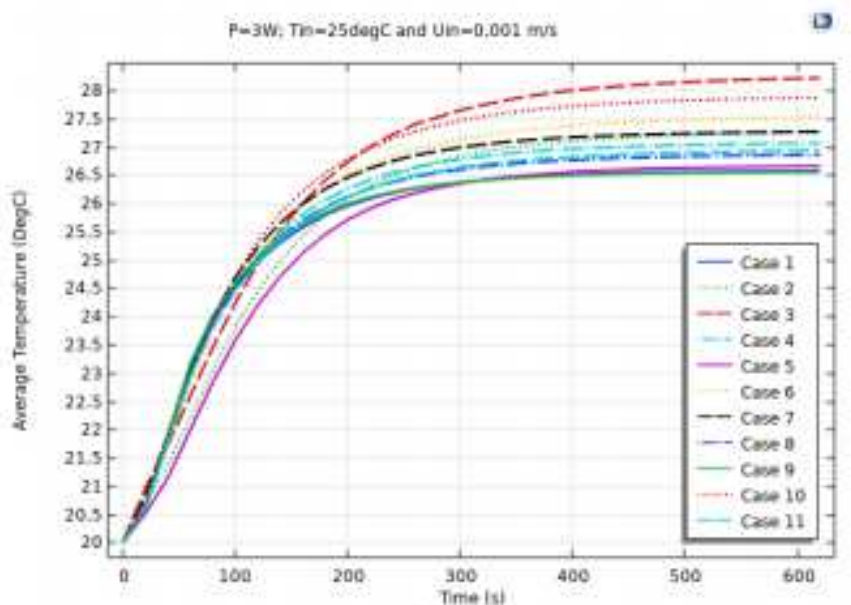

(a)

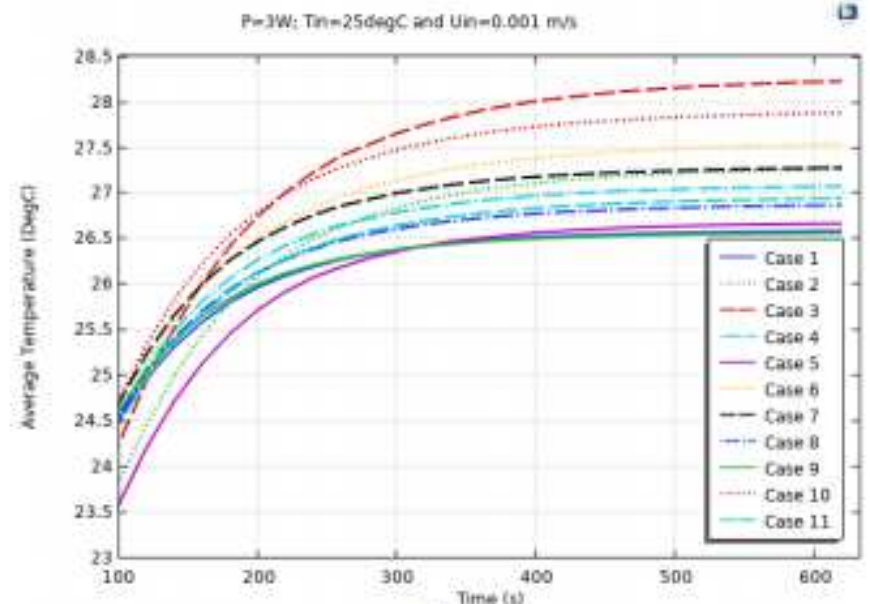

(b)

\section{Figure 9}

Average Temp. when $\mathrm{P}=3 \mathrm{~W}$ for different 11 cases $\mathrm{a}$ ) complete view, $\mathrm{b}$ ) zoomed view 


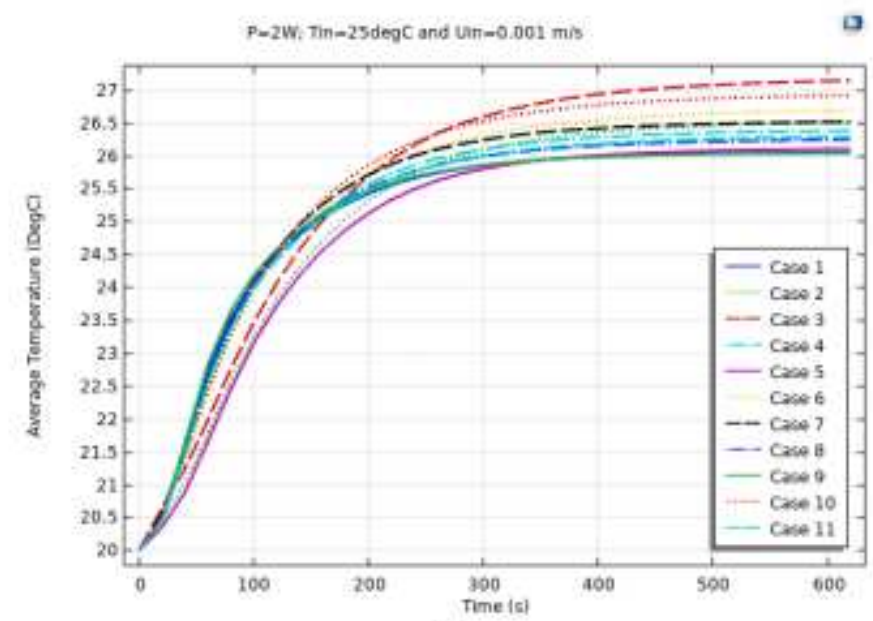

(a)

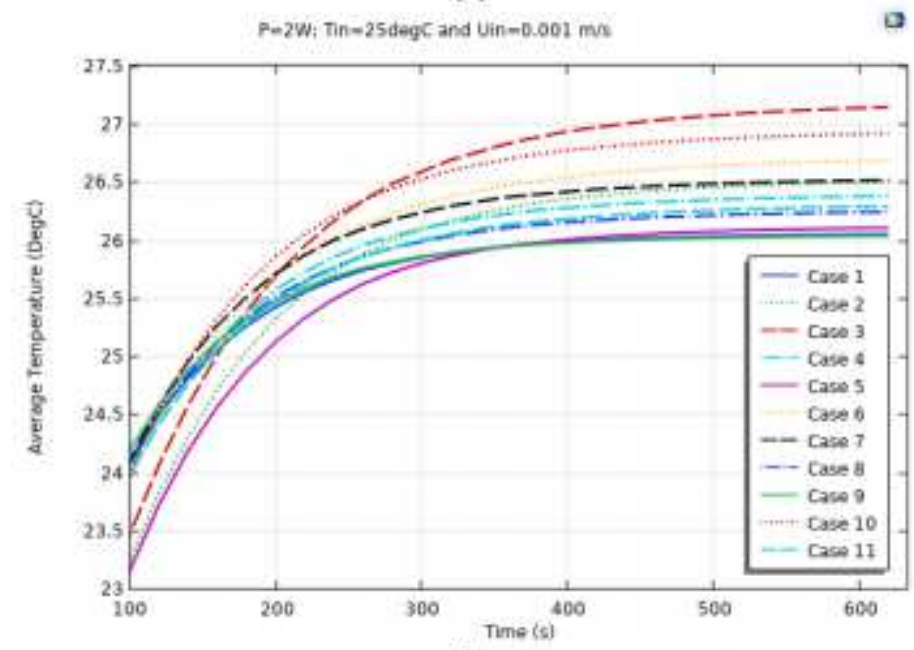

(b)

Figure 10

Average Temp. when $\mathrm{P}=2 \mathrm{~W}$ for different 11 cases $\mathrm{a}$ ) complete view, $\mathrm{b}$ ) zoomed view 


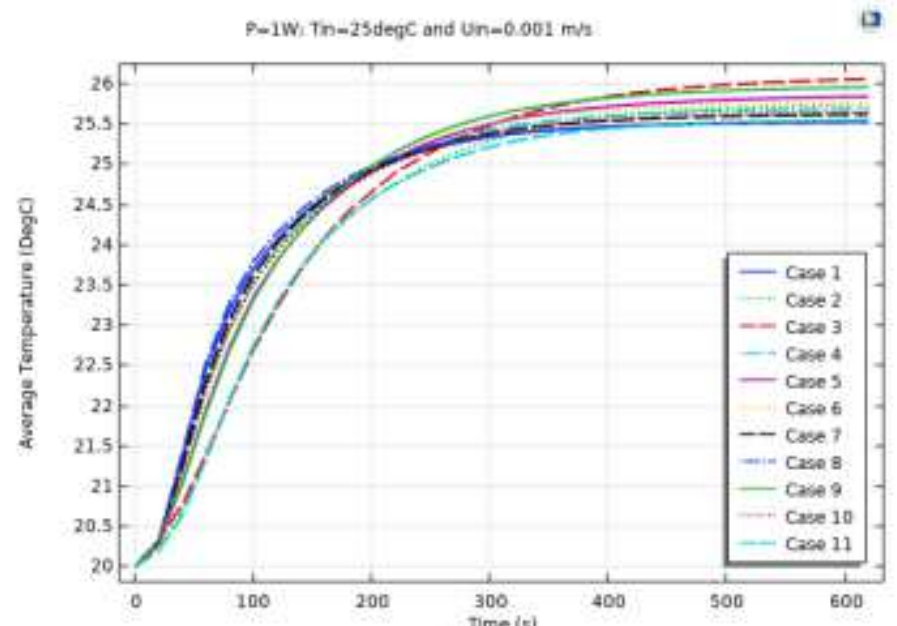

(a)

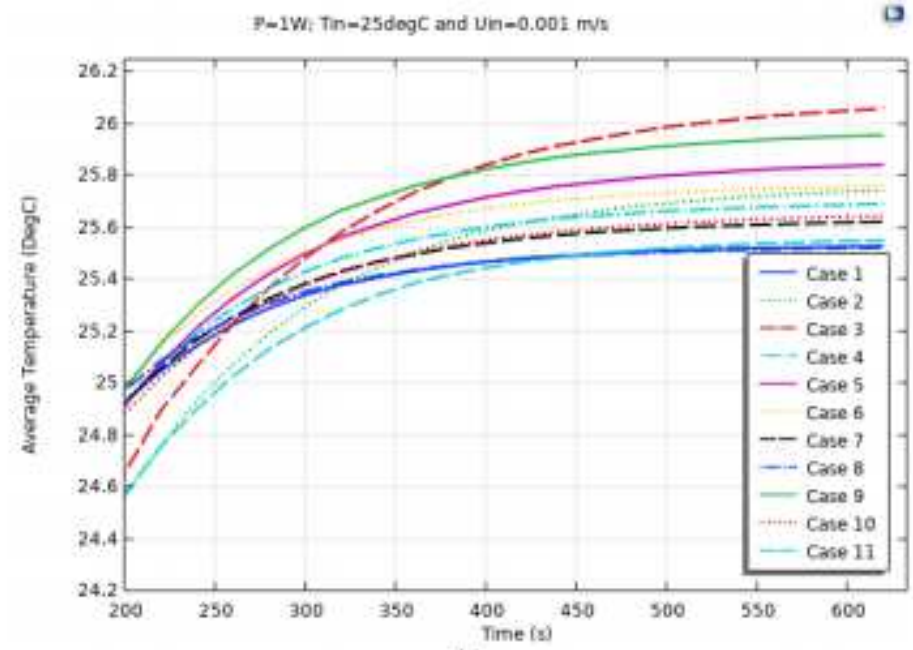

(b)

Figure 11

Average Temp. when $\mathrm{P}=1 \mathrm{~W}$ for different 11 cases a) complete view, b) zoomed view 

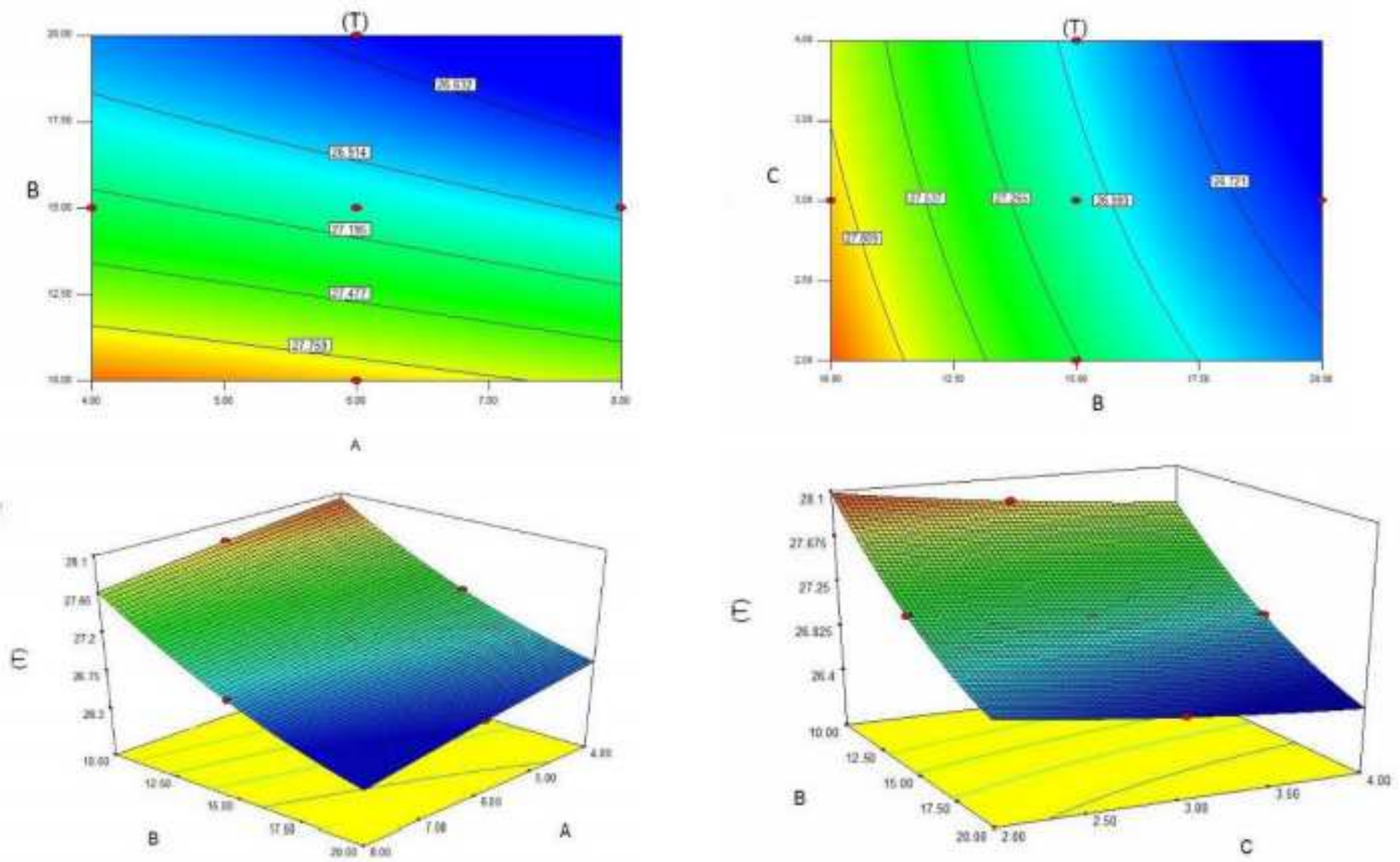

Figure 12

$2 \mathrm{D}$ and $3 \mathrm{D}$ contour of geometry parameters on temperature

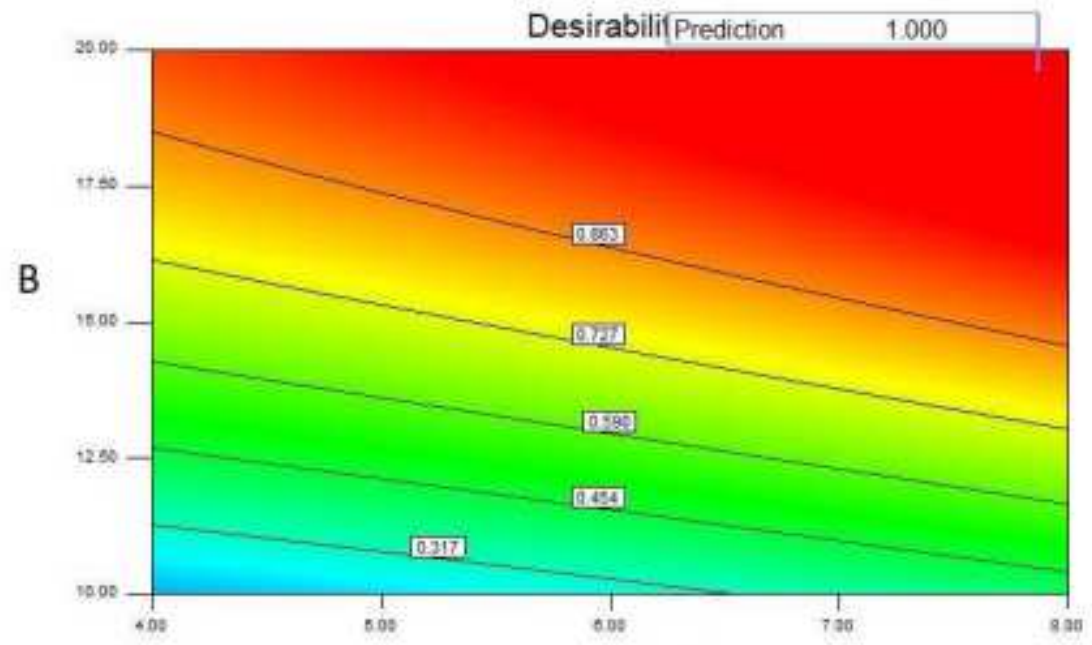

A

Figure 13

Desirability function of optimized geometry 


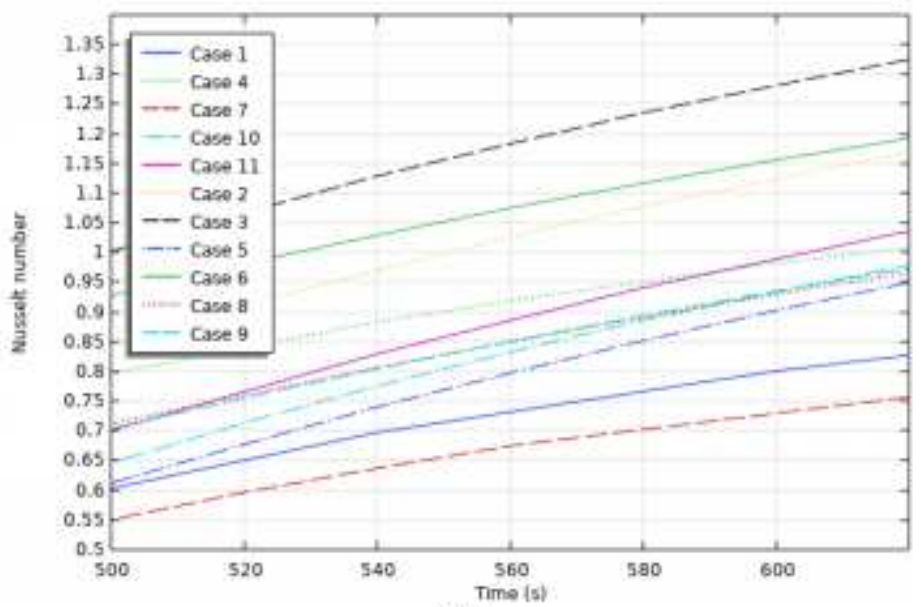

(a)

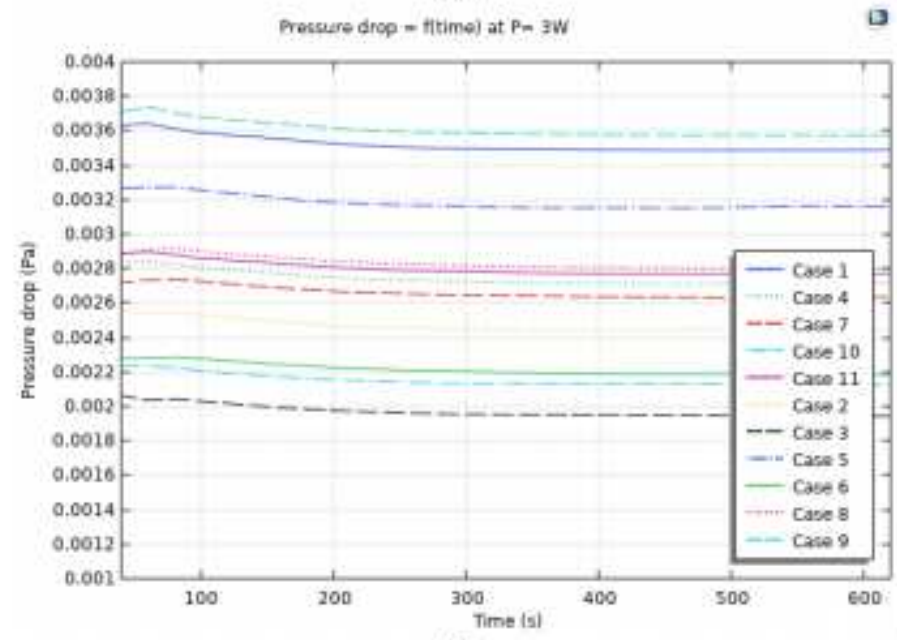

(b)

Figure 14

a) Nusselt number $b$ ) Pressure drops graphs for $\mathrm{P}=3 \mathrm{~W}$ for all designed cases 

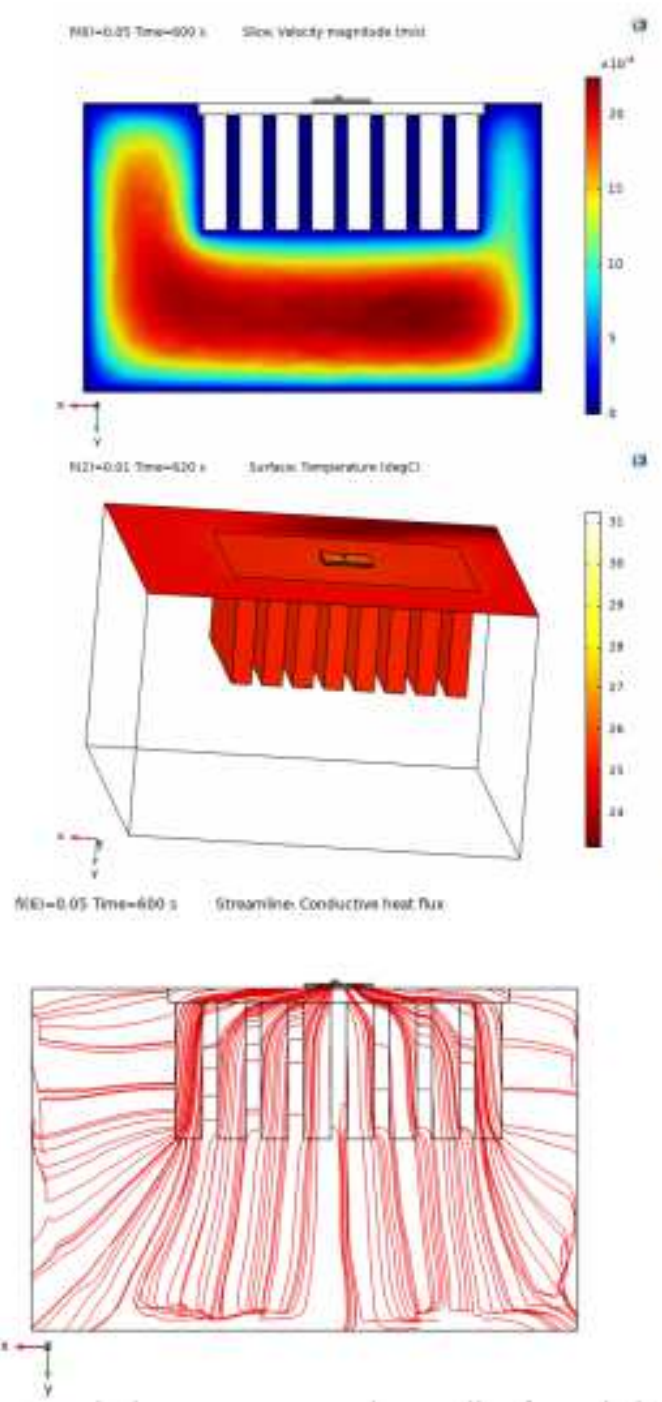

a

Figure 15

Velocity, temperature and streamline for optimized case 

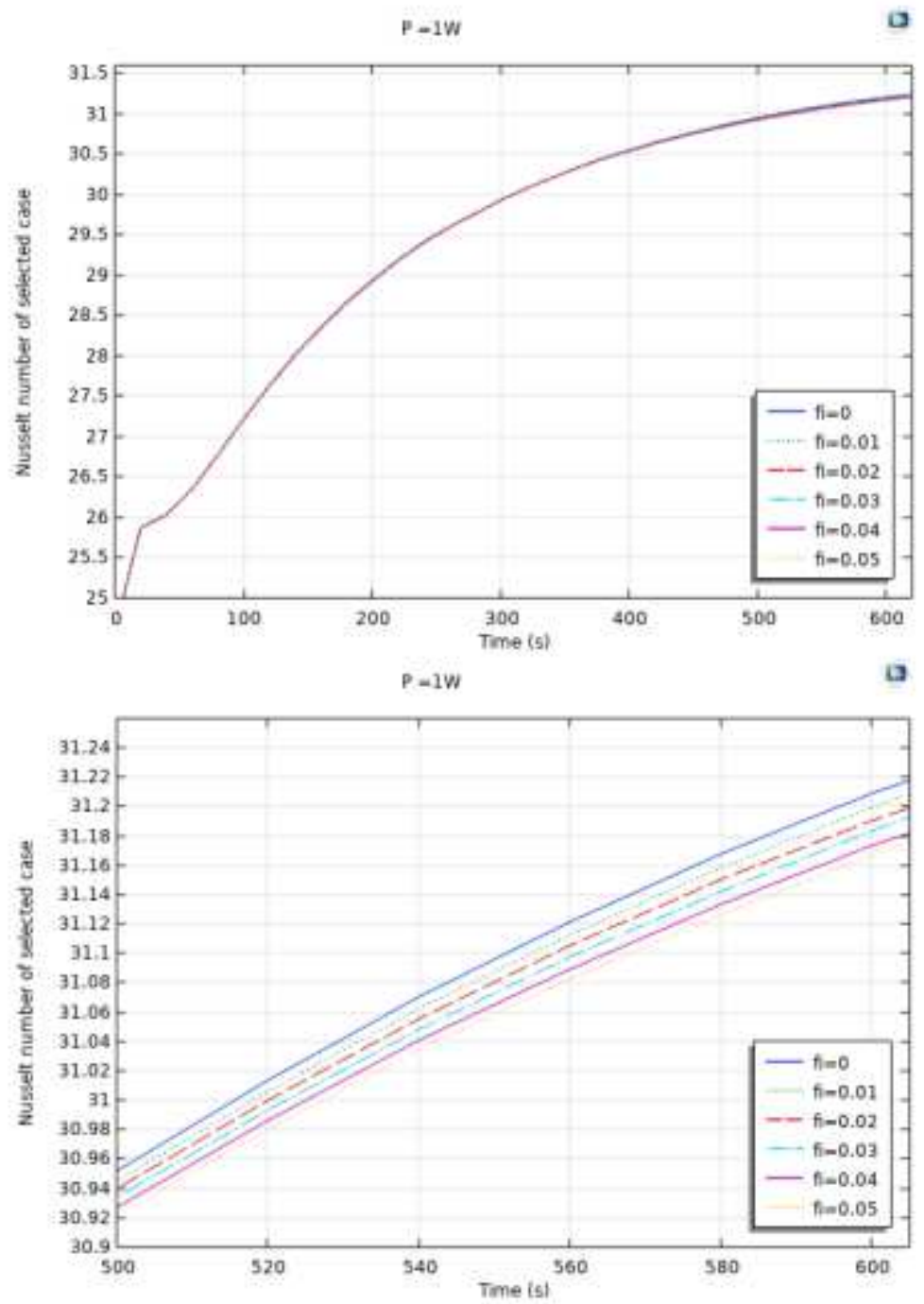

Figure 16

Effect of different nanoparticles concentration on Nusselt number of the optimized case 